\title{
Design, Synthesis and Biological Evaluation of Substituted Pyrimidines as Potential Phosphatidylinositol 3-Kinase (PI3K)
}

\section{Inhibitors}

Ji-Quan Zhang, ${ }^{\dagger, \dagger}$ Yong-Jie Luo, ${ }^{\dagger}$ Yan-Shi Xiong, ${ }^{\dagger}$ Yang Yu, ${ }^{\dagger}$ Zheng-Chao Tu, ${ }^{\S}$ Zi-Jie Long, Xiao-Ju Lai, ${ }^{\perp}$ Hui-Xuan Chen, ${ }^{\dagger}$ Yu Luo, ${ }^{\dagger}$ Jiang Weng, ${ }^{\dagger}$ Gui Lu ${ }^{*}, \dagger, \#$

'Institute of Medicinal Chemsitry, School of Pharmaceutical Sciences, Sun Yat-sen University, Guangzhou, 510006, PR China

${ }^{\ddagger}$ College of Pharmacy, Guizhou Medical University, Guiyang, 550004, PR China

${ }^{\S}$ Guangzhou Institute of Biomedicine and Health, Chinese Academy of Sciences, Guangzhou, 510530, PR China

'Department of Hematology, The Third Affiliated Hospital, Sun Yat-sen University, Guangzhou, 510260, PR China

${ }^{\perp}$ State Key Laboratory of Oncology in South China, Cancer Center, Sun Yat-sen University, Guangzhou, 510060, PR China

"Institute of Human Virology, Sun Yat-sen University, Guangzhou, 510080, PR China

Fax: (+86)-20-39943048

E-mail: lugui@mail.sysu.edu.cn

\section{Supporting information}

1. Synthetic Schemes........................................................

2. Synthesis of intermediates and target compounds...........................S3

3. Enzyme assays..........................................................S23

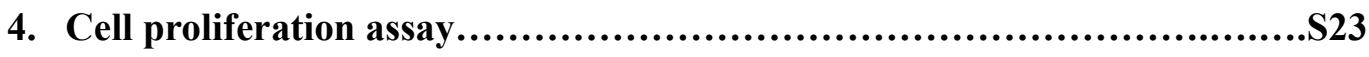

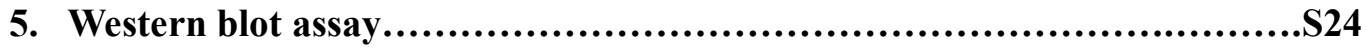

6. Tumor growth in xenografts.............................................

7. ${ }^{1} \mathrm{H}$ NMR and ${ }^{13} \mathrm{C}$ NMR spectra for selected compounds.....................S26 


\section{Synthetic Schemes}<smiles>[R]c1cc(-c2cnc(N)cc2C(F)(F)F)nc([R2])n1</smiles>

2a: $\mathrm{R}^{1}=$ morpholine

2b: $\mathrm{R}^{1}=(2 S, 6 R)-2,6$-dimethylmorpholine

2c: $R^{1}=(4 a R, 7 a S)$-hexahydro-2H-[1,4]dioxino[2,3-c]pyrrole

2d: $R^{1}=( \pm)-(4 a R, 7 a R)$-hexahydro- $2 H-[1,4]$ dioxino[2,3-c]pyrrole

5a: $R^{1}=$ morpholine, $R^{2}=$ morpholine

5b: $R^{1}=$ morpholine, $R^{2}=(2 S, 6 R)-2,6$-dimethylmorpholine

5c: $R^{1}=$ morpholine, $R^{2}=(1 R, 4 R)-2-0 x a-5$-azabicyclo[2.2.1] heptane

5d: $\mathbf{R}^{1}=$ morpholine, $\mathbf{R}^{2}=( \pm)-(4 a S, 7 a S)$-hexahydro- $2 H-[1,4]$ dioxino[2,3-c]pyrrole

5e: $R^{1}=$ morpholine, $R^{2}=(4 a R, 7 a S)$-hexahydro- $2 H-[1,4]$ dioxino[2,3-c]pyrrole

5f: $R^{1}=$ morpholine, $R^{2}=1$-(methylsulfonyl)piperazine

5g: $R^{1}=$ morpholine, $R^{2}=4$-morpholinoaniline

5h: $R^{1}=$ morpholine, $R^{2}=2$-morpholinoethanamine

5i: $R^{1}=(2 S, 6 R)-2,6$-dimethylmorpholine, $R^{2}=$ morpholine

5j: $R^{1}=(2 S, 6 R)-2,6$-dimethylmorpholine, $R^{2}=(2 S, 6 R)-2,6$-dimethylmorpholine

5k: $R^{1}=(2 S, 6 R)-2,6$-dimethylmorpholine, $R^{2}=(4 a R, 7 a S)$-hexahydro-2H-[1,4]dioxino[2,3-c]pyrrole

5I: $\mathrm{R}^{1}=(4 a R, 7 a S)$-hexahydro- $2 H-[1,4]$ dioxino[2,3-c]pyrrole, $\mathrm{R}^{2}=$ morpholine

5m: $\mathrm{R}^{1}=( \pm)-(4 a R, 7 a R)-$ hexahydro-2 $H-[1,4]$ dioxino[2,3-c]pyrrole, $\mathrm{R}^{2}=$ morpholine

$5 n: R^{1}=$ morpholine, $R^{2}=3$-morpholinoaniline

5o: $R^{1}=$ morpholine, $R^{2}=4-(4-($ methylsulfonyl)piperazin-1-yl)aniline

5p: $R^{1}=$ morpholine, $R^{2}=(4-a m i n o p h e n y l)(4-($ methylsulfonyl)piperazin-1-yl)methanone

(a) $\mathrm{R}^{1}$ (1.0 equiv.), DIPEA (1.05 equiv.), $\mathrm{CH}_{2} \mathrm{Cl}_{2},-5{ }^{\circ} \mathrm{C}-\mathrm{rt}, 2.5 \mathrm{~h}, 60-70 \%$; (b) $\mathrm{R}^{2}$ (1.2 equiv.), TEA (1.5 equiv.), Nal (1.5 equiv.), THF/EtOH (1:1), $65^{\circ} \mathrm{C}, 12 \mathrm{~h}, 50-90 \%$ (for aliphatic amines) or $\mathrm{R}^{2}$ (1.0 equiv.), TsOH (1.0 equiv.), $\mathrm{n}-\mathrm{BuOH}, 100{ }^{\circ} \mathrm{C}, 24 \mathrm{~h}, 15-50 \%$ (for aromatic amines); (c) 5-(4,4,5,5-tetramethyl-1,3,2dioxaborolan-2-yl)-4-(trifluoromethyl)pyridin-2-amine (4, 2.0 equiv.), $\mathrm{K}_{2} \mathrm{CO}_{3} \quad(2 \mathrm{M}, \quad 3.0$ equiv.), $\mathrm{Pd}(\mathrm{dppf}) \mathrm{Cl}_{2} \cdot \mathrm{CH}_{2} \mathrm{Cl}_{2}$ (0.05 equiv.), dioxane, $150{ }^{\circ} \mathrm{C}, 2.0-2.5 \mathrm{~h}$, microwave, $5-30 \%$.

\section{Scheme 1.}<smiles>Clc1nc(Cl)nc(Cl)n1</smiles>

8

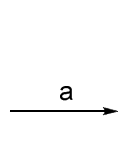

$\overbrace{\mathrm{Cl}}^{\mathrm{N}_{\mathrm{N}}^{\mathrm{N}^{1}}}$

9a-b

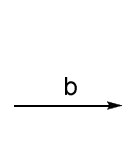<smiles>[R]c1nc([R])nc(Cl)n1</smiles>

10a-e<smiles>[R]c1nc([R])nc(-c2cnc(N)cc2C(F)(F)F)n1</smiles>

11a-e

9a: $R^{1}=$ morpholine

9b: $R^{1}=(2 S, 6 R)-2,6-$ dimethylmorpholine

11a: $R^{1}=$ morpholine, $R^{2}=(1 R, 4 R)-2-$ oxa-5-azabicyclo[2.2.1] heptane

11b: $R^{1}=$ morpholine, $R^{2}=(4 R S, 7 R S)$-hexahydro- $2 H-[1,4]$ dioxino[2,3-c]pyrrole

11c: $R^{1}=(2 S, 6 R)-2,6$-dimethylmorpholine, $R^{2}=(1 R, 4 R)-2-$-oxa-5-azabicyclo[2.2.1] heptane3-c]pyrrole 11d: $R^{1}=(2 S, 6 R)-2,6$-dimethylmorpholine, $R^{2}=(2 S, 6 R)-2,6$-dimethylmorpholine

11e: $R^{1}=(2 S, 6 R)-2,6$-dimethylmorpholine, $R^{2}=(4 a R, 7 a S)$-hexahydro- $2 H-[1,4]$ dioxino[2,3-c]pyrrole

(a) $\mathrm{R}^{1}$ (0.9 equiv.), DIPEA ( 0.9 equiv.), $\mathrm{CH}_{2} \mathrm{Cl}_{2},-5-0{ }^{\circ} \mathrm{C}, 24 \mathrm{~h}, 60-75 \%$; (b) $\mathrm{R}^{2}$ (1.0 equiv.), $\mathrm{K}_{2} \mathrm{CO}_{3}$ (1.5 equiv.), THF, rt, $24 \mathrm{~h}, 75-90 \%$; (c) 4 (2.0 equiv.), $\mathrm{K}_{2} \mathrm{CO}_{3}$ (2 M, 3.0 equiv.), $\mathrm{Pd}(\mathrm{dppf}) \mathrm{Cl}_{2}-\mathrm{CH}_{2} \mathrm{Cl}_{2}$ (0.05 equiv.), dioxane, $150^{\circ} \mathrm{C}, 2.0$ $-2.5 \mathrm{~h}$, microwave, $10-30 \%$.

\section{Scheme 2.}



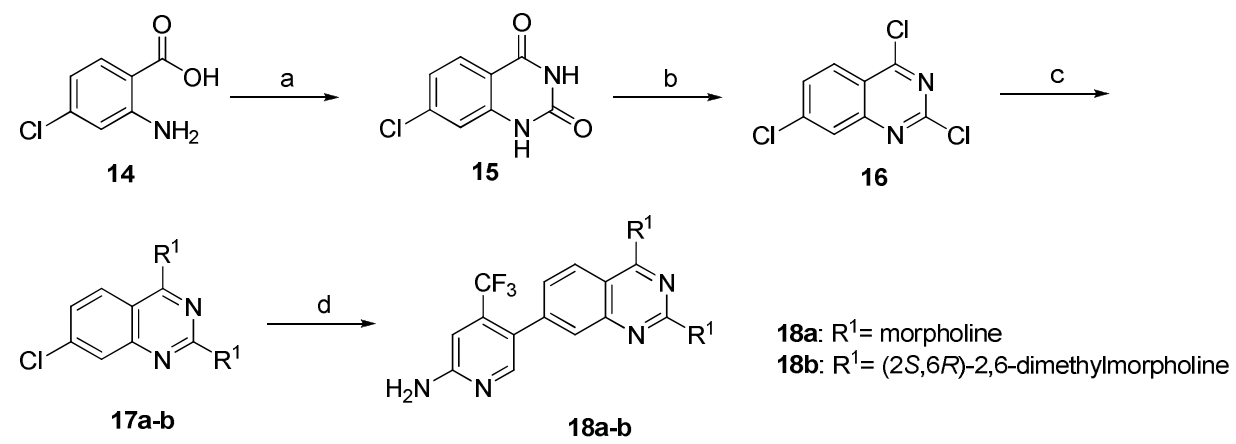

(a) urea (4.0 equiv.), $200^{\circ} \mathrm{C}, 2 \mathrm{~h}, 85 \%$; (b) $\mathrm{POCl}_{3}$ (5.5 equiv.), DIPEA (2.8 equiv.), MeCN, $100{ }^{\circ} \mathrm{C}, 6 \mathrm{~h}, 90 \%$; (c) $\mathrm{R}^{1}$ ( 2.5 equiv.), DIPEA (2.5 equiv.), Nal (2.2 equiv.), DMF, $80^{\circ} \mathrm{C}, 8 \mathrm{~h}, 65-80 \%$; (d) 4 (2.0 equiv.), $\mathrm{K}_{2} \mathrm{CO}_{3}$ (2 M, 3.0 equiv.), $\mathrm{Pd}(\mathrm{dppf}) \mathrm{Cl}_{2} \cdot \mathrm{CH}_{2} \mathrm{Cl}_{2}$ (0.05 equiv.), dioxane, $150^{\circ} \mathrm{C}, 2.0-2.5 \mathrm{~h}$, microwave, $20-30 \%$.

\section{Scheme 3.}

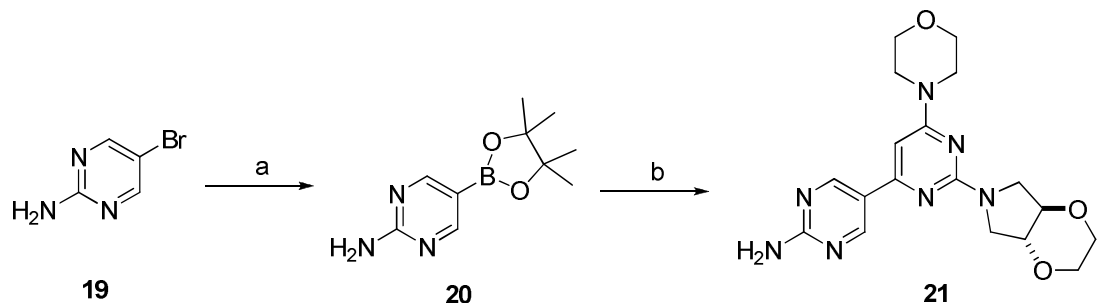

(a) 4,4,4', 4',5,5,5',5'-octamethyl-2,2'-bi(1,3,2-dioxaborolane) (1.1 equiv.), $\mathrm{Pd}$ (dppf) $\mathrm{Cl}_{2} \cdot \mathrm{CH}_{2} \mathrm{Cl}_{2}$ (0.05 equiv.), $\mathrm{KOAc}$ (3.0 equiv.), dioxane, $115^{\circ} \mathrm{C}, 12 \mathrm{~h}, 72 \%$; (b) $3 \mathrm{~d}$ (0.5 equiv.), $\mathrm{K}_{2} \mathrm{CO}_{3}\left(2 \mathrm{M}, 1.5\right.$ equiv.), $\mathrm{Pd}(\mathrm{dppf}) \mathrm{Cl}_{2} \cdot \mathrm{CH}_{2} \mathrm{Cl}_{2}(0.025$ equiv.), dioxane, $150^{\circ} \mathrm{C}, 2.0 \mathrm{~h}$, microwave, $62 \%$.

Scheme 4.

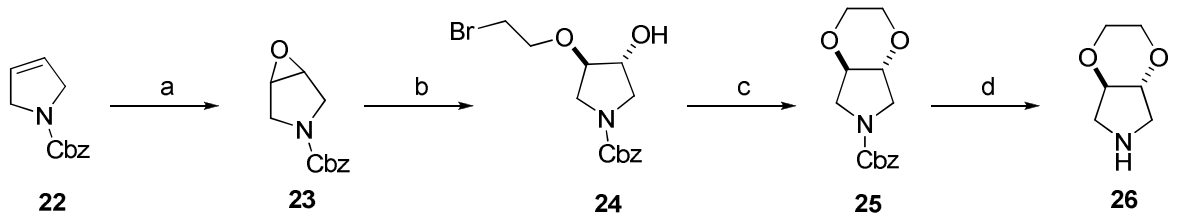

(a) m-CPBA (1.25 equiv.), $\mathrm{CH}_{2} \mathrm{Cl}_{2}, \mathrm{rt}, 16 \mathrm{~h}, 68 \%$; (b) 2-bromoethanol (1.1 equiv.), $\mathrm{BF}_{3} . \mathrm{OEt}_{2}(0.1$ equiv.),

$\mathrm{CH}_{2} \mathrm{Cl}_{2}$, rt, $24 \mathrm{~h}, 29 \%$; (c) $\mathrm{KOH}$ (1.1 equiv.), EtOH, reflux, $6 \mathrm{~h}, 67 \%$; (d) $10 \% \mathrm{Pd} / \mathrm{C}$, THF, rt, $95 \%$.

\section{Scheme 5.}

\section{Synthesis of intermediates and target compounds}

NMR spectra were recorded on a Bruker Avance III spectrometer with TMS as the internal standard and $\mathrm{CDCl}_{3}$ or DMSO- $d_{6}$ as solvent. Low-resolution MS spectra were obtained on an Agilent LC-MS 6120 instrument with an ESI mass detector, and the data were obtained in the positive or negative ion mode. High-resolution ESI-MS data were obtained on a Shimadzu LC-MS-IT-TOF mass spectrometer. The purity of the synthesized compounds was evaluated using a high-performance liquid chromatography (HPLC) equipped with a Chiralcel OD-H, OJ-H or Chiralpak AD-H column (4.6 mm diameter $\times 250 \mathrm{~mm}$ length). The purity of all biologically evaluated compounds was $>95 \%$.

Intermediates 5-(4,4,5,5-tetramethyl-1,3,2-dioxaborolan-2-yl)-4-(trifluoromethyl)pyridin-2-amine (4), 2,4,7trichloroquinazoline (16), 5-(4,4,5,5-tetramethyl-1,3,2-dioxaborolan-2-yl)pyrimidin-2-amine (20), (4aR,7aS)- 
hexahydro- $2 H$-[1,4]dioxino[2,3-c]pyrrole

(27),

$(1 R, 4 R)$-2-oxa-5-azabicyclo[2.2.1] heptanes

(28), 3morpholinoaniline (29), 4-(4-(methylsulfonyl)piperazin-1-yl)aniline (30) and (4-aminophenyl)(4-(methylsulfonyl) piperazin-1-yl)methanone (31) were prepared according to the methods reported previously. ${ }^{1-7}$

\subsection{General procedure for the preparation of 4-substituted-2,6-dichloropyrimidines 2a-d}

DIPEA (1.05 equiv.) was added to a solution of 2,4,6-trichloropyrimidine 1 (1.0 equiv.) in $\mathrm{CH}_{2} \mathrm{Cl}_{2}(10 \mathrm{~mL})$ and cooled to $-5{ }^{\circ} \mathrm{C}$. Then morpholine (1.0 equiv.) was added dropwise. The mixture was stirred at $-5{ }^{\circ} \mathrm{C}$ for $0.5 \mathrm{~h}$ and $\mathrm{rt}$ for $2 \mathrm{~h}$, then $\mathrm{H}_{2} \mathrm{O}(20 \mathrm{~mL})$ was added. The aqueous layer was extracted with $\mathrm{CH}_{2} \mathrm{Cl}_{2}(20 \mathrm{~mL} \times 1)$, the organic layers were combined, washed with brine $(20 \mathrm{~mL} \times 1)$ and dried over $\mathrm{Na}_{2} \mathrm{SO}_{4}$. The organic solvent was removed under reduced pressure, the crude product was purified by column chromatography $(\mathrm{PE} / \mathrm{EtOAc}=4 / 1)$ to afford $\mathbf{2 a}$ as white solid in $65.81 \%$ yield.

Compounds $\mathbf{2 b - d}$ were prepared following the similar procedure with $\mathbf{2 a}$.

\subsubsection{4-(2,6-diChloropyrimidin-4-yl)morpholine $(2 a)^{8}$}

Yield 65.81\%. ESI-MS (m/z): $234.2[\mathrm{M}+\mathrm{H}]^{+} ;{ }^{1} \mathrm{H}$ NMR $\left(400 \mathrm{MHz}, \mathrm{CDCl}_{3}\right) \delta: 6.39(\mathrm{~d}, J=4.5 \mathrm{~Hz}, 1 \mathrm{H})$, $3.88-3.49(\mathrm{~m}, 8 \mathrm{H})$.

\subsection{2 (2R,6S)-4-(2,6-diChloropyrimidin-4-yl)-2,6-dimethylmorpholine (2b)}

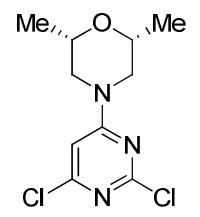

Yield 69.09\%. ESI-MS (m/z): $262.1[\mathrm{M}+\mathrm{H}]^{+} ;{ }^{1} \mathrm{H}$ NMR $\left(400 \mathrm{MHz}, \mathrm{CDCl}_{3}\right) \delta: 6.39(\mathrm{~s}, 1 \mathrm{H}), 3.62(\mathrm{~m}, 2 \mathrm{H}), 2.64(\mathrm{~d}$,

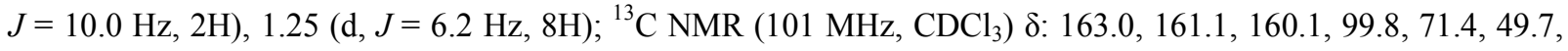
18.9 .

\subsection{3 (4aR,7aS)-6-(2,6-diChloropyrimidin-4-yl)hexahydro-2H-[1,4]dioxino[2,3-c/pyrrole (2c)}

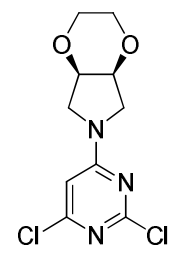

Yield 65.81\%. ESI-MS (m/z): $276.1[\mathrm{M}+\mathrm{H}]^{+} ;{ }^{1} \mathrm{H}$ NMR $\left(400 \mathrm{MHz}, \mathrm{CDCl}_{3}\right) \delta: 6.23(\mathrm{~d}, J=5.6 \mathrm{~Hz}, 1 \mathrm{H}), 4.31(\mathrm{~d}$, $J=38.1 \mathrm{~Hz}, 2 \mathrm{H}), 3.85(\mathrm{dd}, J=10.8,5.4 \mathrm{~Hz}, 3 \mathrm{H}), 3.65(\mathrm{ddd}, J=28.4,14.4,9.2 \mathrm{~Hz}, 4 \mathrm{H}), 3.50-3.39(\mathrm{~m}, 1 \mathrm{H}) ;{ }^{13} \mathrm{C}$ NMR (101 MHz, $\left.\mathrm{CDCl}_{3}\right) \delta: 162.0,159.7,159.6,100.3,72.6,72.0,62.9,61.7,48.0,47.1$.

\subsection{4 (土)-(4aR,7aR)-6-(2,6-diChloropyrimidin-4-yl)hexahydro-2H-[1,4]dioxino[2,3-c/pyrrole (2d)}<smiles>Clc1cc(N2CC3OCCOC3C2)nc(Cl)n1</smiles>

Yield 60.28\%. ESI-MS (m/z): $276.0[\mathrm{M}+\mathrm{H}]^{+} ;{ }^{1} \mathrm{H}$ NMR (400 MHz, $\left.\mathrm{CDCl}_{3}\right) \delta: 6.21(\mathrm{~s}, 1 \mathrm{H}), 4.11(\mathrm{dd}, J=16.6$, 
$6.3 \mathrm{~Hz}, 1 \mathrm{H}), 3.95-3.55(\mathrm{~m}, 7 \mathrm{H}), 3.24(\mathrm{dt}, J=19.1,10.1 \mathrm{~Hz}, 2 \mathrm{H}) ;{ }^{13} \mathrm{C} \mathrm{NMR}\left(101 \mathrm{MHz}, \mathrm{CDCl}_{3}\right) \delta: 162.2,159.9$, $159.8,100.1,67.1,47.0,46.7$.

\subsection{General procedure for the preparation of 2,4-disubstituted-6-chloro-pyrimidines $3 a-f, 3 h-m$}

Morpholine (1.0 equiv.) was added to a solution of 4-substituted-2,6-dichloropyrimidine (1.1 equiv.) in THF/EtOH (10 mL, 1:1), followed by the addition of TEA (1.2 equiv.) and NaI (1.1 equiv.). The solution was stirred at $65{ }^{\circ} \mathrm{C}$ for $12 \mathrm{~h}$. Then the solvent was removed, the residue was dissolved in EtOAc $(50 \mathrm{~mL})$, washed with $\mathrm{H}_{2} \mathrm{O}(30 \mathrm{~mL})$ and brine $(30 \mathrm{~mL})$ in turn, dried over $\mathrm{Na}_{2} \mathrm{SO}_{4}$. The solvent was removed under reduced pressure, the crude product was purified by column chromatography $(\mathrm{PE} / \mathrm{EtOAc}=5 / 1)$ to afford 3a as white solid in $63.51 \%$ yield.

Compounds $\mathbf{3 b}-\mathbf{f}, \mathbf{3 h}-\mathbf{m}$ were prepared following the similar procedure with $\mathbf{3 a}$.

\subsubsection{4,4'-(6-Chloropyrimidine-2,4-diyl)dimorpholine $(3 a)^{9}$}

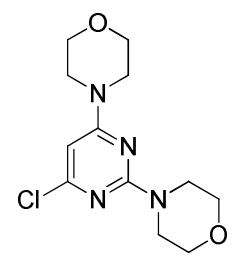

Yield 63.51\%. ESI-MS $(m / z): 285.2[\mathrm{M}+\mathrm{H}]^{+} ;{ }^{1} \mathrm{H}$ NMR $\left(400 \mathrm{MHz}, \mathrm{CDCl}_{3}\right) \delta: 5.86(\mathrm{~d}, J=1.1 \mathrm{~Hz}, 1 \mathrm{H})$, 3.82-3.64 (m, 12H), 3.59-3.50 (m, 4H).

\subsection{2 (2R,6S)-4-(4-Chloro-6-morpholinopyrimidin-2-yl)-2,6-dimethylmorpholine (3b)}<smiles>CC1CN(c2nc(Cl)cc(N3CCOCC3)n2)CC(C)O1</smiles>

Yield 58.21\%. ESI-MS $(\mathrm{m} / \mathrm{z}): 313.2[\mathrm{M}+\mathrm{H}]^{+} ;{ }^{1} \mathrm{H}$ NMR $\left(400 \mathrm{MHz}, \mathrm{CDCl}_{3}\right) \delta: 5.84(\mathrm{~d}, J=1.8 \mathrm{~Hz}, 1 \mathrm{H}), 4.45(\mathrm{~d}$, $J=13.3 \mathrm{~Hz}, 2 \mathrm{H}), 3.80-3.68(\mathrm{~m}, 4 \mathrm{H}), 3.68-3.46(\mathrm{~m}, 6 \mathrm{H}), 2.53(\mathrm{t}, J=11.3 \mathrm{~Hz}, 2 \mathrm{H}), 1.23(\mathrm{dd}, J=6.2,1.7 \mathrm{~Hz}, 6 \mathrm{H})$; ${ }^{13} \mathrm{C}$ NMR $\left(101 \mathrm{MHz}, \mathrm{CDCl}_{3}\right) \delta: 164.0,160.7,160.6,91.1,71.7,66.5,49.3,44.5,18.9$.

\subsection{3 (1R,4R)-5-(4-Chloro-6-morpholinopyrimidin-2-yl)-2-oxa-5-azabicyclo[2.2.1]heptane (3c)}<smiles>Clc1cc(N2CCOCC2)nc(N2C3COC2C3)n1</smiles>

Yield 66.22\%. ESI-MS (m/z): $297.1[\mathrm{M}+\mathrm{H}]]^{+} ;{ }^{1} \mathrm{H}$ NMR (400 MHz, $\left.\mathrm{CDCl}_{3}\right) \delta: 5.84(\mathrm{~s}, 1 \mathrm{H}), 4.96(\mathrm{~s}, 1 \mathrm{H}), 4.64(\mathrm{~s}$, 1H), 3.84 (s, 2H), 3.73 (s, 4H), 3.54 (s, 6H), 1.89 (s, 2H); $\left.{ }^{13} \mathrm{C} \mathrm{NMR} \mathrm{(101} \mathrm{MHz,} \mathrm{CDCl}\right)$ ) : 163.3, 160.4, 159.8, 91.1, 76.6, 74.0, 66.5, 56.9, 55.6, 44.4, 36.6.

\subsection{4 \\ (土)-(4aS,7aS)-6-(4-Chloro-6-morpholinopyrimidin-2-yl)hexahydro-2H-[1,4]dioxino[2,3-clpyrrole (3d)}




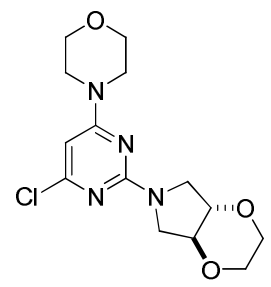

Yield 52.34\%. ESI-MS $(\mathrm{m} / \mathrm{z}): 327.1[\mathrm{M}+\mathrm{H}]^{+} ;{ }^{1} \mathrm{H}$ NMR $\left(400 \mathrm{MHz}, \mathrm{CDCl}_{3}\right) \delta: 5.87(\mathrm{~s}, 1 \mathrm{H}), 3.96(\mathrm{~s}, 2 \mathrm{H})$, 3.90-3.81 (m, 5H), 3.77-3.64 (m, 7H), 3.58-3.51 (m, 4H); ${ }^{13} \mathrm{C}$ NMR (101 MHz, $\left.\mathrm{CDCl}_{3}\right) \delta: 163.3,160.4,159.5,91.0$, $78.1,67.2,66.3,46.4,44.4$.

\subsection{5 (4aR,7aS)-6-(4-Chloro-6-morpholinopyrimidin-2-yl)hexahydro-2H-[1,4]dioxino[2,3-c]pyrrole (3e)}

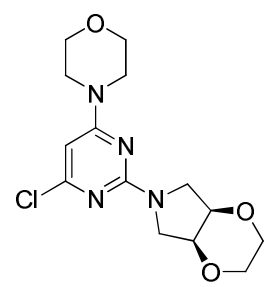

Yield 68.09\%. ESI-MS $(\mathrm{m} / \mathrm{z})$ : $327.2[\mathrm{M}+\mathrm{H}]^{+} ;{ }^{1} \mathrm{H}$ NMR (400 MHz, $\left.\mathrm{CDCl}_{3}\right) \delta: 5.85(\mathrm{~s}, 1 \mathrm{H}), 4.23(\mathrm{~s}, 2 \mathrm{H})$,

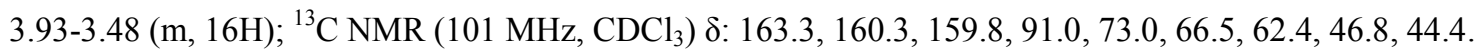

\subsubsection{4-(6-Chloro-2-(4-(methylsulfonyl)piperazin-1-yl)pyrimidin-4-yl)morpholine (3f)}

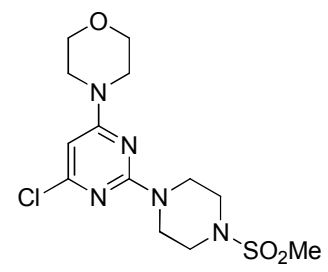

Yield 50.65\%. ESI-MS $(\mathrm{m} / \mathrm{z}): 362.1[\mathrm{M}+\mathrm{H}]]^{+} ;{ }^{1} \mathrm{H}$ NMR $\left(400 \mathrm{MHz}, \mathrm{CDCl}_{3}\right) \delta: 5.89(\mathrm{~d}, J=2.8 \mathrm{~Hz}, 1 \mathrm{H}), 3.90(\mathrm{~d}$, $J=3.6 \mathrm{~Hz}, 4 \mathrm{H}), 3.80-3.70(\mathrm{~m}, 4 \mathrm{H}), 3.55(\mathrm{~s}, 4 \mathrm{H}), 3.24(\mathrm{~d}, J=4.0 \mathrm{~Hz}, 4 \mathrm{H}), 2.78(\mathrm{~d}, J=2.8 \mathrm{~Hz}, 3 \mathrm{H}) ;{ }^{13} \mathrm{C}$ NMR $(101$ $\left.\mathrm{MHz}, \mathrm{CDCl}_{3}\right) \delta: 163.5,160.7,160.5,91.8,66.8,45.8,44.5,43.5,34.5$.

\subsubsection{4-Chloro-6-morpholino-N-(2-morpholinoethyl)pyrimidin-2-amine (3h)}<smiles></smiles>

Yield 73.65\%. ESI-MS $(\mathrm{m} / \mathrm{z}): 328.2[\mathrm{M}+\mathrm{H}]^{+} ;{ }^{1} \mathrm{H}$ NMR $\left(400 \mathrm{MHz}, \mathrm{CDCl}_{3}\right) \delta: 5.85(\mathrm{~s}, 1 \mathrm{H}), 5.49(\mathrm{~s}, 1 \mathrm{H})$, 3.77-3.66 (m, 9H), 3.58-3.51 (m, 5H), $2.53(\mathrm{t}, J=5.7 \mathrm{~Hz}, 2 \mathrm{H}), 2.45(\mathrm{~s}, 4 \mathrm{H}) ;{ }^{13} \mathrm{C} \mathrm{NMR}\left(101 \mathrm{MHz}, \mathrm{CDCl}_{3}\right) \delta: 164.0$, $161.3,160.7,91.1,66.9,66.5,57.3,53.4,44.4,37.6$.

\subsection{8 (2R,6S)-4-(6-Chloro-2-morpholinopyrimidin-4-yl)-2,6-dimethylmorpholine (3i)}




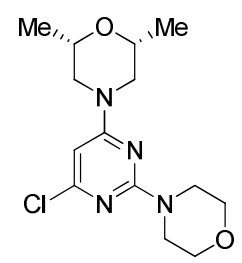

Yield 78.45\%. ESI-MS (m/z): $313.2[\mathrm{M}+\mathrm{H}]^{+} ;{ }^{1} \mathrm{H}$ NMR (400 MHz, $\left.\mathrm{CDCl}_{3}\right) \delta: 5.85(\mathrm{~d}, J=5.2 \mathrm{~Hz}, 1 \mathrm{H}), 4.03(\mathrm{~s}$, 2H), $3.68(\mathrm{t}, J=23.9 \mathrm{~Hz}, 10 \mathrm{H}), 2.54(\mathrm{td}, J=12.7,4.9 \mathrm{~Hz}, 2 \mathrm{H}), 1.23(\mathrm{t}, J=5.6 \mathrm{~Hz}, 6 \mathrm{H}) ;{ }^{13} \mathrm{C} \mathrm{NMR}(101 \mathrm{MHz}$, $\left.\mathrm{CDCl}_{3}\right) \delta: 163.1,160.9,160.5,91.4,71.7,66.9,49.3,44.8,18.9$.

\subsection{9 (2R,2'R,6S,6'S)-4,4'-(6-Chloropyrimidine-2,4-diyl)bis(2,6-dimethylmorpholine) (3j)}<smiles>CC1CN(c2cc(Cl)nc(N3CC(C)OC(C)C3)n2)CC(C)O1</smiles>

Yield 86.15\%. ESI-MS (m/z): $341.2[\mathrm{M}+\mathrm{H}]^{+} ;{ }^{1} \mathrm{H}$ NMR $\left(400 \mathrm{MHz}, \mathrm{CDCl}_{3}\right) \delta: 5.84(\mathrm{~s}, 1 \mathrm{H}), 4.44(\mathrm{~d}, J=12.8 \mathrm{~Hz}$, 2H), $4.02(\mathrm{~s}, 2 \mathrm{H}), 3.68-3.51(\mathrm{~m}, 4 \mathrm{H}), 2.61-2.43(\mathrm{~m}, 4 \mathrm{H}), 1.24(\mathrm{dd}, J=6.1,3.4 \mathrm{~Hz}, 12 \mathrm{H}) ;{ }^{13} \mathrm{C} \mathrm{NMR}(101 \mathrm{MHz}$, $\left.\mathrm{CDCl}_{3}\right) \delta: 163.1,160.6,160.5,91.1,71.7,71.4,49.6,49.5,18.9$.

2.2.10 (4aR,7aS)-6-(4-Chloro-6-((2R,6S)-2,6-dimethylmorpholino)pyrimidin-2-yl)hexahydro-2H-[1,4]dioxino [2,3-c]pyrrole (3k)

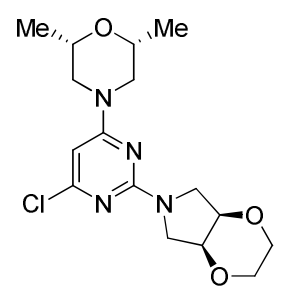

Yield 74.45\%. ESI-MS (m/z): $355.2[\mathrm{M}+\mathrm{H}]^{+} ;{ }^{1} \mathrm{H}$ NMR (400 MHz, $\left.\mathrm{CDCl}_{3}\right) \delta: 5.85(\mathrm{~d}, J=5.3 \mathrm{~Hz}, 1 \mathrm{H}), 4.16(\mathrm{~d}$, $J=63.9 \mathrm{~Hz}, 4 \mathrm{H}), 3.93-3.53(\mathrm{~m}, 10 \mathrm{H}), 2.55(\mathrm{t}, J=9.4 \mathrm{~Hz}, 2 \mathrm{H}), 1.24(\mathrm{t}, J=5.7 \mathrm{~Hz}, 6 \mathrm{H}) ;{ }^{13} \mathrm{C} \mathrm{NMR}(101 \mathrm{MHz}$, $\left.\mathrm{CDCl}_{3}\right) \delta: 162.9,160.2,159.9,91.0,72.8,71.6,62.6,49.1,47.1,18.7$.

\subsubsection{1 (4aR,7aS)-6-(6-Chloro-2-morpholinopyrimidin-4-yl)hexahydro-2H-[1,4]dioxino[2,3-c]pyrrole (3l)}<smiles>Clc1cc(N2CC3OCCOC3C2)nc(N2CCOCC2)n1</smiles>

Yield 72.37\%. ESI-MS (m/z): $327.1[\mathrm{M}+\mathrm{H}]^{+} ;{ }^{1} \mathrm{H}$ NMR (400 MHz, $\left.\mathrm{CDCl}_{3}\right) \delta: 5.68(\mathrm{~d}, J=4.4 \mathrm{~Hz}, 1 \mathrm{H}), 4.24(\mathrm{~s}$, 2H), 3.97-3.37 (m, 16H); ${ }^{13} \mathrm{C} \mathrm{NMR}\left(101 \mathrm{MHz}, \mathrm{CDCl}_{3}\right) \delta: 162.1,160.9,159.8,91.5,72.8,67.0,62.6,47.1,44.1$. 
(3m)

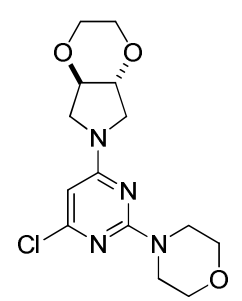

Yield 75.29\%. ESI-MS $(\mathrm{m} / \mathrm{z}): 327.1[\mathrm{M}+\mathrm{H}]^{+} ;{ }^{1} \mathrm{H}$ NMR $\left(400 \mathrm{MHz}, \mathrm{CDCl}_{3}\right) \delta: 5.66(\mathrm{~s}, 1 \mathrm{H}), 3.91-3.83(\mathrm{~m}, 4 \mathrm{H})$, 3.80-3.57 (m, 12H), 3.17 (s, 2H); ${ }^{13} \mathrm{C}$ NMR (101 MHz, $\left.\mathrm{CDCl}_{3}\right)$ 8: 161.9, 160.8, 159.8, 91.2, 77.8, 67.2, 66.8, 46.2, 44.3 .

\subsection{General procedure for the preparation of 2,4-disubstituted-6-chloro-pyrimidines $3 g, 3 n, 3 o$ and $3 p$}

To a solution of $2 \mathrm{a}$ (1.0 equiv.) in $n$ - $\mathrm{BuOH}(20 \mathrm{~mL}$ ) was added 4-morpholinoaniline (1.0 equiv.), followed by the addition of $\mathrm{TsOH} \cdot \mathrm{H}_{2} \mathrm{O}$ (1.0 equiv.). After the mixture was stirred at $100 \square$ for $24 \mathrm{~h}$, the solvent was removed, the residue was dissolved in EtOAc $(50 \mathrm{~mL})$, washed with $\mathrm{H}_{2} \mathrm{O}(50 \mathrm{~mL})$ and brine $(50 \mathrm{~mL})$ in turn, dried over $\mathrm{Na}_{2} \mathrm{SO}_{4}$. The solvent was removed under reduced pressure, the residue was purified by column chromatography $(\mathrm{PE} / \mathrm{EtOAc}=1 / 1)$ to afford $\mathbf{3 g}$ as gray solid in $53.54 \%$ yield.

Compounds 3n, 3o-p were prepared following the similar procedure mentioned above.

\subsubsection{4-Chloro-6-morpholino-N-(4-morpholinophenyl)pyrimidin-2-amine (3g)}<smiles>Clc1cc(Nc2ccc(N3CCOCC3)cc2)nc(N2CCOCC2)c1</smiles>

Yield 53.54\%. ESI-MS (m/z): $376.2[\mathrm{M}+\mathrm{H}]^{+}$; ${ }^{1} \mathrm{H}$ NMR (400 MHz, $\left.\mathrm{CDCl}_{3}\right) \delta: 7.45-7.36(\mathrm{~m}, 2 \mathrm{H}), 6.89(\mathrm{~d}, J=$ $7.4 \mathrm{~Hz}, 2 \mathrm{H}), 6.83$ (s, 1H), 5.97 (d, $J=1.5 \mathrm{~Hz}, 1 \mathrm{H}), 3.89-3.82(\mathrm{~m}, 4 \mathrm{H}), 3.78-3.72(\mathrm{~m}, 4 \mathrm{H}), 3.57$ (s, 4H), 3.14-3.07 (m, 4H); ${ }^{13} \mathrm{C}$ NMR (101 MHz, $\left.\mathrm{CDCl}_{3}\right) \delta: 163.7,160.3,159.1,147.2,132.2,121.2,116.4,92.6,66.9,66.4,50.1$, 44.5.

\subsubsection{4-Chloro-6-morpholino-N-(3-morpholinophenyl)pyrimidin-2-amine (3n)}<smiles>Clc1cc(Nc2cccc(N3CCOCC3)c2)nc(N2CCOCC2)c1</smiles>

Yield 34.90\%. ESI-MS (m/z): $376.1[\mathrm{M}+\mathrm{H}]^{+} ;{ }^{1} \mathrm{H}$ NMR (400 MHz, DMSO- $\left.d_{6}\right) \delta: 9.35(\mathrm{~s}, 1 \mathrm{H}), 7.38(\mathrm{~s}, 1 \mathrm{H})$, 7.13-7.01 (m, 2H), $6.55(\mathrm{~d}, J=6.8 \mathrm{~Hz}, 1 \mathrm{H}), 6.32(\mathrm{~s}, 1 \mathrm{H}), 3.77-3.70(\mathrm{~m}, 4 \mathrm{H}), 3.69-3.58(\mathrm{~m}, 8 \mathrm{H}), 3.09-3.01(\mathrm{~m}, 4 \mathrm{H})$;

${ }^{13} \mathrm{C}$ NMR (101 MHz, DMSO- $\left.d_{6}\right) \delta: 163.2,159.1,158.7,151.4,140.6,128.8,110.4,109.0,106.0,92.2,66.1,65.6$, 48.6, 44.3.

\subsubsection{4-Chloro-N-(4-(4-(methylsulfonyl)piperazin-1-yl)phenyl)-6-morpholinopyrimidin-2-amine (3o)}




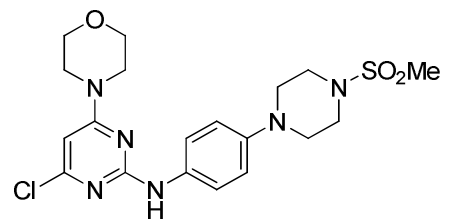

Yield 14.60\%. ESI-MS (m/z): $453.2[\mathrm{M}+\mathrm{H}]]^{+} ;{ }^{1} \mathrm{H}$ NMR (400 MHz, $\left.\mathrm{CDCl}_{3}\right) \delta: 7.42(\mathrm{~d}, J=8.9 \mathrm{~Hz}, 2 \mathrm{H}), 6.91(\mathrm{~d}$, $J=8.9 \mathrm{~Hz}, 2 \mathrm{H}), 6.83(\mathrm{~s}, 1 \mathrm{H}), 5.99(\mathrm{~s}, 1 \mathrm{H}), 3.80-3.72(\mathrm{~m}, 4 \mathrm{H}), 3.58(\mathrm{~d}, J=4.7 \mathrm{~Hz}, 4 \mathrm{H}), 3.42-3.35(\mathrm{~m}, 4 \mathrm{H})$, 3.27-3.20 (m, 4H), $2.83(\mathrm{~s}, 3 \mathrm{H}) ;{ }^{13} \mathrm{C}$ NMR $\left(101 \mathrm{MHz}, \mathrm{CDCl}_{3}\right) \delta: 163.6,160.3,159.1,146.4,133.2,121.2,118.0$, $92.8,66.4,50.3,46.1,44.5,34.8$.

\subsection{4 (4-((4-Chloro-6-morpholinopyrimidin-2-yl)amino)phenyl)(4-(methylsulfonyl)piperazin-1-yl) methanone (3p)}

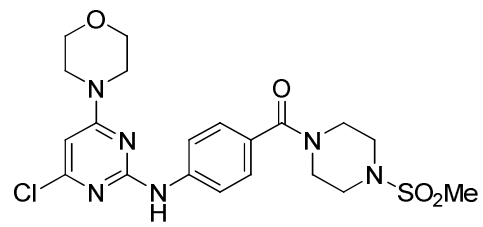

Yield 15.30\%. ESI-MS (m/z): $481.2[\mathrm{M}+\mathrm{H}]^{+} ;{ }^{1} \mathrm{H}$ NMR (400 MHz, DMSO- $\left.d_{6}\right) \delta: 9.72(\mathrm{~s}, 1 \mathrm{H}), 7.73(\mathrm{~d}, J=8.4$ $\mathrm{Hz}, 2 \mathrm{H}), 7.37(\mathrm{~d}, J=8.3 \mathrm{~Hz}, 2 \mathrm{H}), 6.41(\mathrm{~s}, 1 \mathrm{H}), 3.73-3.54(\mathrm{~m}, 12 \mathrm{H}), 3.16(\mathrm{~s}, 4 \mathrm{H}), 2.90(\mathrm{~s}, 3 \mathrm{H}) ;{ }^{13} \mathrm{C} \mathrm{NMR}(101 \mathrm{MHz}$, DMSO- $\left.d_{6}\right) \delta: 169.3,163.2,159.3,158.6,141.9,128.1,127.7,118.1,95.5,65.7,45.6,44.6,42.0,34.0$.

\subsection{General procedure for the preparation of 2,4,6-trisubstituted pyrimidines5a-m}

To a solution of 3a-m (1.0 equiv.), 5-(4,4,5,5-tetramethyl-1,3,2-dioxaborolan-2-yl)-4-(trifluoromethyl)pyridin2-amine (4, 2.0 equiv.) and $\mathrm{Pd}(\mathrm{dppf}) \mathrm{Cl}_{2} \cdot \mathrm{CH}_{2} \mathrm{Cl}_{2}\left(0.05\right.$ equiv.) in degassed dioxane $(6 \mathrm{~mL})$ was added $2 \mathrm{M} \mathrm{K}_{2} \mathrm{CO}_{3}$ (3.0 equiv.). The mixture was heated under microwave at $150{ }^{\circ} \mathrm{C}$ for $2.0-2.5 \mathrm{~h}$. The solvent was removed, the residue was dissolved in EtOAc $(50 \mathrm{~mL})$, washed with $\mathrm{H}_{2} \mathrm{O}(30 \mathrm{~mL} \times 3)$ and brine $(30 \mathrm{~mL})$ in turn, dried over $\mathrm{Na}_{2} \mathrm{SO}_{4}$. The solvent was removed under reduced pressure, the residue was first separated by column chromatography $(\mathrm{PE} / \mathrm{EtOAc}=5 / 1$ to $1 / 2)$, then further purified by column chromatography $\left(\mathrm{CH}_{2} \mathrm{Cl}_{2} / \mathrm{MeOH}=50 / 1\right)$ to afford white or off-white solid in 5-30\% yield.

\subsubsection{5-(2,6-diMorpholinopyrimidin-4-yl)-4-(trifluoromethyl)pyridin-2-amine (5a) ${ }^{1}$}<smiles>Nc1cc(-c2cc(N3CCOCC3)nc(N3CCOCC3)n2)ccn1</smiles>

Yield 27.78\%. HPLC purity 99.31\% (Chiralcel OD-H, $0.5 \mathrm{~mL} / \mathrm{min}$, hexane $/ i-\mathrm{PrOH}=60 / 40, t=12.86 \mathrm{~min}$ ). HRMS (ESI): $m / z[\mathrm{M}+\mathrm{H}]^{+}$calcd. for $\left[\mathrm{C}_{18} \mathrm{H}_{22} \mathrm{~F}_{3} \mathrm{~N}_{6} \mathrm{O}_{2}\right]^{+}: 411.1751$, found: $411.1736 ;{ }^{1} \mathrm{H} \mathrm{NMR}\left(400 \mathrm{MHz}, \mathrm{CDCl}_{3}\right) \delta$ : $8.24(\mathrm{~s}, 1 \mathrm{H}), 6.77(\mathrm{~s}, 1 \mathrm{H}), 5.96(\mathrm{~s}, 1 \mathrm{H}), 4.88(\mathrm{~s}, 2 \mathrm{H}), 3.74(\mathrm{dd}, J=12.0,4.0 \mathrm{~Hz}, 12 \mathrm{H}), 3.59(\mathrm{~d}, J=4.0 \mathrm{~Hz}, 4 \mathrm{H}) ;{ }^{13} \mathrm{C}$ $\operatorname{NMR}\left(101 \mathrm{MHz}, \mathrm{CDCl}_{3}\right)$ \&: 163.3, 161.4, 159.4, 150.6, 137.7, 131.6, 128.7, 123.8, 105.7, 92.8, 67.0, 66.6, 44.4, 30.9 . 


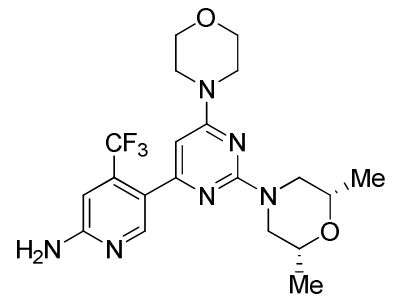

Yield 22.05\%. HPLC purity $96.10 \%$ (Chiralcel OD-H, $0.5 \mathrm{~mL} / \mathrm{min}$, hexane $/ i-\mathrm{PrOH}=60 / 40, t=9.34 \mathrm{~min}$ ). HRMS (ESI): $m / z[\mathrm{M}+\mathrm{H}]^{+}$calcd. for $\left[\mathrm{C}_{20} \mathrm{H}_{26} \mathrm{~F}_{3} \mathrm{~N}_{6} \mathrm{O}_{2}\right]^{+}: 439.2064$, found: $439.2070 ;{ }^{1} \mathrm{H} \mathrm{NMR}\left(400 \mathrm{MHz}, \mathrm{CDCl}_{3}\right) \delta$ : $8.26(\mathrm{~s}, 1 \mathrm{H}), 6.77(\mathrm{~s}, 1 \mathrm{H}), 5.95(\mathrm{~s}, 1 \mathrm{H}), 4.83(\mathrm{~s}, 2 \mathrm{H}), 4.54(\mathrm{~d}, J=12.7 \mathrm{~Hz}, 2 \mathrm{H}), 3.86-3.70(\mathrm{~m}, 4 \mathrm{H}), 3.71-3.50(\mathrm{~m}$, $6 \mathrm{H}), 2.54(\mathrm{dd}, J=13.1,10.7 \mathrm{~Hz}, 2 \mathrm{H}), 1.22(\mathrm{~d}, J=6.2 \mathrm{~Hz}, 6 \mathrm{H}) ;{ }^{13} \mathrm{C} \mathrm{NMR}\left(101 \mathrm{MHz}, \mathrm{CDCl}_{3}\right) \delta: 163.3,162.6,161.1$, $158.4,151.0,138.4,124.8,121.5,105.4,92.4,72.0,66.5,49.7,44.5,18.9$.

\subsubsection{5-(2-((1R,4R)-2-Oxa-5-azabicyclo[2.2.1]heptan-5-yl)-6-morpholinopyrimidin-4-yl)-4-(trifluoromethyl) pyridin-2-amine (5c)}

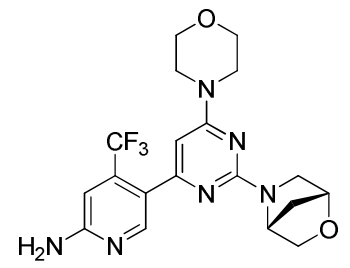

Yield 20.15\%. HPLC purity 97.20\% (Chiralcel OD-H, $0.5 \mathrm{~mL} / \mathrm{min}$, hexane $/ i-\mathrm{PrOH}=60 / 40, t=12.58 \mathrm{~min}$ ). HRMS (ESI): $m / z[\mathrm{M}+\mathrm{H}]^{+}$calcd. for $\left[\mathrm{C}_{19} \mathrm{H}_{22} \mathrm{~F}_{3} \mathrm{~N}_{6} \mathrm{O}_{2}\right]^{+}: 423.1751$, found: $423.1772 ;{ }^{1} \mathrm{H} \mathrm{NMR}\left(400 \mathrm{MHz}, \mathrm{CDCl}_{3}\right) \delta$ : $8.25(\mathrm{~s}, 1 \mathrm{H}), 6.76(\mathrm{~s}, 1 \mathrm{H}), 5.94(\mathrm{~s}, 1 \mathrm{H}), 4.99(\mathrm{~s}, 1 \mathrm{H}), 4.83(\mathrm{~s}, 2 \mathrm{H}), 4.64(\mathrm{~s}, 1 \mathrm{H}), 3.87(\mathrm{dd}, J=20.0,7.2 \mathrm{~Hz}, 2 \mathrm{H})$, 3.81-3.66 (m, 5H), 3.62-3.56 (m, 5H), $1.90(\mathrm{~s}, 2 \mathrm{H}) ;{ }^{13} \mathrm{C} \mathrm{NMR}\left(101 \mathrm{MHz}, \mathrm{CDCl}_{3}\right) \delta: 163.0,160.7,158.8,151.0$, $147.4,138.1,124.4,121.9,105.3,92.1,73.3,67.2,56.8,55.5,53.2,44.8,36.4$.

\subsection{4 (士)-5-(2-((4aS,7aR)-diHydro-2H-[1,4]dioxino[2,3-c]pyrrol-6(3H,7H,7aH)-yl)-6-morpholinopyrimidin- 4-yl)-4-(trifluoromethyl)pyridin-2-amine (5d)}

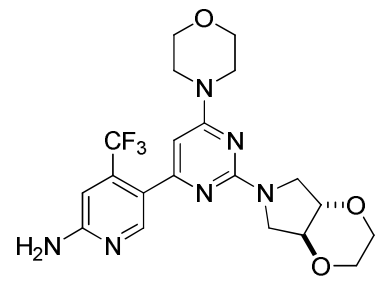

Yield 16.97\%. HPLC purity 98.92\% (Chiralcel OD-H, $0.5 \mathrm{~mL} / \mathrm{min}$, hexane $/ i-\mathrm{PrOH}=60 / 40, t=16.89$ and $18.06 \mathrm{~min}$ ). HRMS (ESI): $\mathrm{m} / z[\mathrm{M}+\mathrm{H}]^{+}$calcd. for $\left[\mathrm{C}_{20} \mathrm{H}_{24} \mathrm{~F}_{3} \mathrm{~N}_{6} \mathrm{O}_{3}\right]^{+}: 453.1856$, found: $453.1852 ;{ }^{1} \mathrm{H}$ NMR (400 $\left.\mathrm{MHz}, \mathrm{CDCl}_{3}\right) \delta: 8.25(\mathrm{~s}, 1 \mathrm{H}), 6.76(\mathrm{~s}, 1 \mathrm{H}), 5.95(\mathrm{~s}, 1 \mathrm{H}), 5.29(\mathrm{~s}, 1 \mathrm{H}), 4.82(\mathrm{~s}, 2 \mathrm{H}), 4.01(\mathrm{~s}, 2 \mathrm{H}), 3.87(\mathrm{~s}, 3 \mathrm{H})$, 3.79-3.70 (m, 6H), 3.63-3.56 (m, 4H), $3.26(\mathrm{t}, J=10.0 \mathrm{~Hz}, 2 \mathrm{H}) ;{ }^{13} \mathrm{C} \mathrm{NMR}\left(101 \mathrm{MHz}, \mathrm{CDCl}_{3}\right) \delta: 163.0,160.7$, $159.1,150.3,138.1,124.4,121.9,105.3,100.1,93.0,78.8,67.8,66.5,46.8,44.2$. 


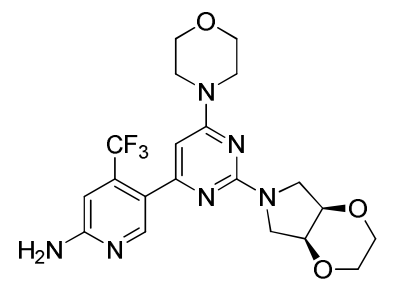

Yield 15.05\%. HPLC purity 95.60\% (Chiralcel OJ-H, $0.5 \mathrm{~mL} / \mathrm{min}$, hexane $/ i-\mathrm{PrOH}=60 / 40, t=15.16 \mathrm{~min}$ ). HRMS (ESI): $m / z[\mathrm{M}+\mathrm{H}]^{+}$calcd. for $\left[\mathrm{C}_{20} \mathrm{H}_{24} \mathrm{~F}_{3} \mathrm{~N}_{6} \mathrm{O}_{3}\right]^{+}: 453.1856$, found: 453.1838; ${ }^{1} \mathrm{H} \mathrm{NMR}\left(400 \mathrm{MHz}, \mathrm{CDCl}_{3}\right) \delta$ : $8.25(\mathrm{~d}, J=4.5 \mathrm{~Hz}, 1 \mathrm{H}), 6.75(\mathrm{~d}, J=4.5 \mathrm{~Hz}, 1 \mathrm{H}), 5.94(\mathrm{~d}, J=4.9 \mathrm{~Hz}, 1 \mathrm{H}), 4.84(\mathrm{~s}, 2 \mathrm{H}), 4.25$ (d, $J=3.9 \mathrm{~Hz}, 2 \mathrm{H})$, 3.94-3.55 (m, 16H); ${ }^{13} \mathrm{C} \mathrm{NMR}\left(101 \mathrm{MHz}, \mathrm{CDCl}_{3}\right) \delta: 163.0,162.7,160.3,158.7,150.9,138.4,124.4,121.5,105.3$, 92.4, 73.3, 67.2, 62.9, 47.4, 44.5.

\subsubsection{5-(2-(4-(Methylsulfonyl)piperazin-1-yl)-6-morpholinopyrimidin-4-yl)-4-(trifluoromethyl)pyridin-2- amine (5f)}

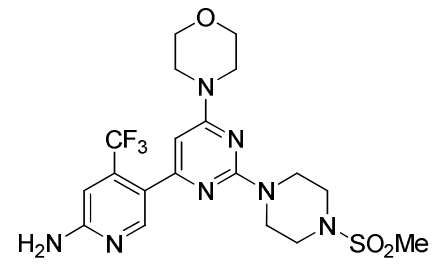

Yield 14.54\%. HPLC purity 97.34\% (Chiralpak AD-H, $0.5 \mathrm{~mL} / \mathrm{min}$, hexane $/ i-\mathrm{PrOH}=60 / 40, t=25.56 \mathrm{~min}$ ). HRMS (ESI): $m / z$ [M-H] $]^{-}$calcd. for $\left[\mathrm{C}_{19} \mathrm{H}_{23} \mathrm{~F}_{3} \mathrm{~N}_{7} \mathrm{O}_{3} \mathrm{~S}\right]=486.1507$, found: $486.1498 ;{ }^{1} \mathrm{H}$ NMR $\left(400 \mathrm{MHz}, \mathrm{CDCl}_{3}\right) \delta$ : $8.23(\mathrm{~s}, 1 \mathrm{H}), 6.79(\mathrm{~s}, 1 \mathrm{H}), 5.98(\mathrm{~s}, 1 \mathrm{H}), 4.94(\mathrm{~s}, 2 \mathrm{H}), 3.99-3.89(\mathrm{~m}, 4 \mathrm{H}), 3.84-3.74(\mathrm{~m}, 4 \mathrm{H}), 3.66-3.53(\mathrm{~m}, 4 \mathrm{H})$, 3.31-3.20 (m, 4H), 2.77 (s, 3H); ${ }^{13} \mathrm{C}$ NMR (101 MHz, $\left.\mathrm{CDCl}_{3}\right)$ 8: 163.3, 162.9, 160.9, 158.8, 150.7, 144.3, 137.7, $124.1,105.4,92.7,66.6,45.8,44.3,43.6,34.3$.

\subsubsection{4-(6-Amino-4-(trifluoromethyl)pyridin-3-yl)-6-morpholino-N-(4-morpholinophenyl)pyrimidin-2-amine} (5g)<smiles>Nc1cc(-c2cc(N3CCOCC3)nc(Nc3ccc(N4CCOCC4)cc3)n2)c(C(F)(F)F)cn1</smiles>

Yield 9.50\%. HPLC purity $98.96 \%$ (Chiralcel OD-H, $0.5 \mathrm{~mL} / \mathrm{min}$, hexane $/ i-\mathrm{PrOH}=60 / 40, t=20.80 \mathrm{~min}$ ). HRMS (ESI): $m / z[\mathrm{M}+\mathrm{H}]^{+}$calcd. for $\left[\mathrm{C}_{24} \mathrm{H}_{27} \mathrm{~F}_{3} \mathrm{~N}_{7} \mathrm{O}_{2}\right]^{+}: 502.2173$, found: $502.2163 ;{ }^{1} \mathrm{H} \mathrm{NMR}\left(400 \mathrm{MHz}, \mathrm{CDCl}_{3}\right) \delta$ : $8.27(\mathrm{~s}, 1 \mathrm{H}), 7.47$ (d, J=7.7 Hz, 2H), 6.92-6.85 (m, 3H), $6.76(\mathrm{~s}, 1 \mathrm{H}), 6.06(\mathrm{~s}, 1 \mathrm{H}), 4.84(\mathrm{~s}, 2 \mathrm{H}), 3.88-3.83(\mathrm{~m}, 4 \mathrm{H})$, 3.81-3.76 (m, 4H), $3.62(\mathrm{~d}, J=4.0 \mathrm{~Hz}, 4 \mathrm{H}), 3.13-3.07(\mathrm{~m}, 4 \mathrm{H}) ;{ }^{13} \mathrm{C} \mathrm{NMR}\left(101 \mathrm{MHz}, \mathrm{CDCl}_{3}\right) \delta: 163.3,163.0,159.6$, 158.7, 151.0, 146.8, 137.7, 137.3, 133.1, 123.9, 120.8, 116.6, 104.8, 94.7, 67.0, 66.7, 50.3, 44.4. 
<smiles>Nc1cc(C(F)(F)F)cc(-c2cc(N3CCOCC3)nc(NCCN3CCOCC3)n2)n1</smiles>

Yield 8.41\%. HPLC purity 98.57\% (Chiralcel OD-H, $0.5 \mathrm{~mL} / \mathrm{min}$, hexane $/ i-\mathrm{PrOH}=60 / 40, t=11.40 \mathrm{~min}$ ). HRMS (ESI): $m / z[\mathrm{M}+\mathrm{H}]^{+}$calcd. for $\left[\mathrm{C}_{20} \mathrm{H}_{27} \mathrm{~F}_{3} \mathrm{~N}_{7} \mathrm{O}_{2}\right]^{+}: 454.2173$, found: $454.2142 ;{ }^{1} \mathrm{H} \mathrm{NMR}\left(400 \mathrm{MHz}, \mathrm{CDCl}_{3}\right) \delta$ : $8.24(\mathrm{~s}, 1 \mathrm{H}), 6.75(\mathrm{~s}, 1 \mathrm{H}), 5.94(\mathrm{~s}, 1 \mathrm{H}), 5.37$ (s, 1H), $4.79(\mathrm{~s}, 2 \mathrm{H}), 3.82-3.65(\mathrm{~m}, 8 \mathrm{H}), 3.63-3.56(\mathrm{~m}, 4 \mathrm{H}), 3.50$ (dd, $J$ $=11.4,5.7 \mathrm{~Hz}, 2 \mathrm{H}), 2.56(\mathrm{t}, J=6.0 \mathrm{~Hz}, 2 \mathrm{H}), 2.47(\mathrm{~s}, 4 \mathrm{H}) ;{ }^{13} \mathrm{C} \mathrm{NMR}\left(101 \mathrm{MHz}, \mathrm{CDCl}_{3}\right) \delta: 163.2,163.0,161.8$, $158.6,150.8,137.7,131.6,124.1,105.0,93.1,67.0,66.6,57.6,53.5,44.2,37.7$.

\subsubsection{5-(6-((2S,6R)-2,6-diMethylmorpholino)-2-morpholinopyrimidin-4-yl)-4-(trifluoromethyl)pyridin-2-} amine (5i)<smiles>CO[C@H]1CN(c2cc(-c3cnc(N)cc3C(F)(F)F)nc(N3CCOCC3)n2)C[C@@H](C)O1</smiles>

Yield 14.30\%. HPLC purity 96.30\% (Chiralcel OJ-H, $0.5 \mathrm{~mL} / \mathrm{min}$, hexane $/ i-\mathrm{PrOH}=60 / 40, t=7.91 \mathrm{~min}$ ). HRMS (ESI): $m / z[\mathrm{M}+\mathrm{H}]^{+}$calcd. for $\left[\mathrm{C}_{20} \mathrm{H}_{26} \mathrm{~F}_{3} \mathrm{~N}_{6} \mathrm{O}_{2}\right]^{+}: 439.2064$, found: 439.2072; ${ }^{1} \mathrm{H} \mathrm{NMR}\left(400 \mathrm{MHz}, \mathrm{CDCl}_{3}\right) \delta$ : $8.25(\mathrm{~s}, 1 \mathrm{H}), 6.77(\mathrm{~s}, 1 \mathrm{H}), 5.96(\mathrm{~s}, 1 \mathrm{H}), 4.84(\mathrm{~s}, 2 \mathrm{H}), 4.23-4.04(\mathrm{~m}, 2 \mathrm{H}), 3.87-3.57(\mathrm{~m}, 10 \mathrm{H}), 2.66-2.51(\mathrm{~m}, 2 \mathrm{H})$, $1.25(\mathrm{~d}, J=6.2 \mathrm{~Hz}, 6 \mathrm{H}) ;{ }^{13} \mathrm{C}$ NMR $\left(101 \mathrm{MHz}, \mathrm{CDCl}_{3}\right) \delta: 162.8,161.5,158.8,150.9,138.0,137.6,124.4,121.5$, $105.2,92.7,71.7,67.2,50.0,44.5,18.9$.

\subsubsection{5-(2,6-bis((2S,6R)-2,6-diMethylmorpholino)pyrimidin-4-yl)-4-(trifluoromethyl)pyridin-2-amine (5j)}<smiles>C[C@H]1CN(c2cc(-c3cnc(N)cc3C(F)(F)F)nc(N3C[C@H](C)O[C@H](C)C3)n2)C[C@@H](O)O1</smiles>

Yield 5.35\%. HPLC purity 97.82\% (Chiralcel OJ-H, $0.5 \mathrm{~mL} / \mathrm{min}$, hexane $/ i-\mathrm{PrOH}=60 / 40, t=7.22 \mathrm{~min}$ ). HRMS (ESI): $m / z[\mathrm{M}+\mathrm{H}]^{+}$calcd. for $\left[\mathrm{C}_{22} \mathrm{H}_{30} \mathrm{~F}_{3} \mathrm{~N}_{6} \mathrm{O}_{2}\right]^{+}: 467.2377$, found: 467.2308; ${ }^{1} \mathrm{H}$ NMR $\left(400 \mathrm{MHz}, \mathrm{CDCl}_{3}\right) \delta$ : $8.27(\mathrm{~s}, 1 \mathrm{H}), 6.78(\mathrm{~s}, 1 \mathrm{H}), 5.94(\mathrm{~s}, 1 \mathrm{H}), 4.80(\mathrm{~s}, 2 \mathrm{H}), 4.54(\mathrm{~d}, J=12.8 \mathrm{~Hz}, 2 \mathrm{H}), 4.12(\mathrm{~d}, J=12.2 \mathrm{~Hz}, 2 \mathrm{H}), 3.74-3.58$ (m, 4H), 2.68-2.46 (m, 4H), 1.25 (dd, $J=10.7,6.2 \mathrm{~Hz}, 12 \mathrm{H}) ;{ }^{13} \mathrm{C}$ NMR $\left(101 \mathrm{MHz}, \mathrm{CDCl}_{3}\right) \delta: 162.9,162.7,161.2$, $158.7,150.9,138.1,131.9,124.5,105.0,92.4,71.7,49.7,18.9$.

\subsubsection{5-(2-((4aR,7aS)-diHydro-2H-[1,4]dioxino[2,3-c]pyrrol-6(3H,7H,7aH)-yl)-6-((2R,6S)-2,6-dimethyl}




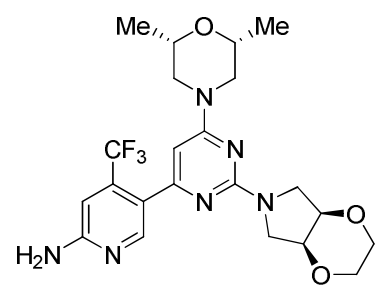

Yield 22.42\%. HPLC purity 98.35\% (Chiralcel OJ-H, $0.5 \mathrm{~mL} / \mathrm{min}$, hexane $/ i-\mathrm{PrOH}=60 / 40, t=9.20 \mathrm{~min}$ ). HRMS (ESI): $m / z[\mathrm{M}+\mathrm{H}]^{+}$calcd. for $\left[\mathrm{C}_{22} \mathrm{H}_{28} \mathrm{~F}_{3} \mathrm{~N}_{6} \mathrm{O}_{3}\right]^{+}: 481.2170$, found: 481.2149; ${ }^{1} \mathrm{H} \mathrm{NMR}\left(400 \mathrm{MHz}, \mathrm{CDCl}_{3}\right) \delta$ : $8.26(\mathrm{~d}, J=4.0 \mathrm{~Hz}, 1 \mathrm{H}), 6.77(\mathrm{~d}, J=4.0 \mathrm{~Hz}, 1 \mathrm{H}), 5.93(\mathrm{~d}, J=4.3 \mathrm{~Hz}, 1 \mathrm{H}), 4.78(\mathrm{~s}, 2 \mathrm{H}), 4.34-3.97(\mathrm{~m}, 4 \mathrm{H})$, 3.96-3.55 (m, 10H), $2.56(\mathrm{dd}, J=16.2,7.3 \mathrm{~Hz}, 2 \mathrm{H}), 1.29-1.17(\mathrm{~m}, 6 \mathrm{H}) ;{ }^{13} \mathrm{C} \mathrm{NMR}\left(101 \mathrm{MHz}, \mathrm{CDCl}_{3}\right) \delta: 162.7$, $162.6,160.4,158.8,151.0,138.1,124.8,121.2,105.3,92.4,73.3,71.7,62.6,49.7,46.0,19.3$.

\subsubsection{5-(6-((4aR,7aS)-diHydro-2H-[1,4]dioxino[2,3-c]pyrrol-6(3H,7H,7aH)-yl)-2-morpholinopyrimidin-4-} yl)-4-(trifluoromethyl)pyridin-2-amine (5l)

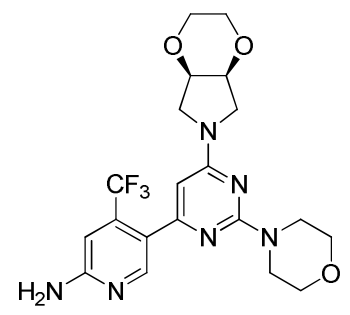

Yield 23.35\%. HPLC purity 95.61\% (Chiralcel OD-H, $0.5 \mathrm{~mL} / \mathrm{min}$, hexane $/ i$-PrOH $=60 / 40, t=11.40 \mathrm{~min}$ ). HRMS (ESI): $m / z[\mathrm{M}+\mathrm{H}]^{+}$calcd. for $\left[\mathrm{C}_{20} \mathrm{H}_{24} \mathrm{~F}_{3} \mathrm{~N}_{6} \mathrm{O}_{3}\right]^{+}: 453.1856$, found: 453.1876; ${ }^{1} \mathrm{H} \mathrm{NMR}\left(400 \mathrm{MHz} \mathrm{CDCl}_{3}\right) \delta$ : $8.25(\mathrm{~s}, 1 \mathrm{H}), 6.76(\mathrm{~s}, 1 \mathrm{H}), 5.95(\mathrm{~s}, 1 \mathrm{H}), 4.82(\mathrm{~s}, 2 \mathrm{H}), 4.01(\mathrm{~s}, 2 \mathrm{H}), 3.87(\mathrm{~s}, 2 \mathrm{H}), 3.80-3.67(\mathrm{~m}, 6 \mathrm{H}), 3.64-3.52(\mathrm{~m}$, 5H), $3.26(\mathrm{~m}, 3 \mathrm{H}) ;{ }^{13} \mathrm{C}$ NMR $\left(101 \mathrm{MHz}, \mathrm{CDCl}_{3}\right) \delta: 161.6,159.1,154.3,151.0,150.1,127.0,124.4,109.8,105.0$, 93.0, 72.7, 67.1, 62.9, 46.8, 44.5.

2.4.13 (土)-5-(6-((4aR,7aR)-diHydro-2H-[1,4]dioxino[2,3-c]pyrrol-6(3H,7H,7aH)-yl)-2-morpholinopyrimidin4-yl)-4-(trifluoromethyl)pyridin-2-amine (5m)

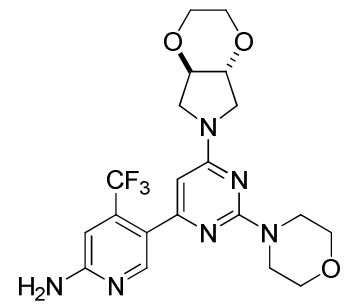

Yield 10.44\%. HPLC purity 97.02\% (Chiralcel OJ-H, $0.5 \mathrm{~mL} / \mathrm{min}$, hexane $/ i-\mathrm{PrOH}=60 / 40, t=14.03 \mathrm{~min}$ ). HRMS (ESI): $m / z[\mathrm{M}+\mathrm{H}]^{+}$calcd. for $\left[\mathrm{C}_{20} \mathrm{H}_{24} \mathrm{~F}_{3} \mathrm{~N}_{6} \mathrm{O}_{3}\right]^{+}: 453.1856$, found: 453.1836; ${ }^{1} \mathrm{H} \mathrm{NMR}\left(400 \mathrm{MHz} \mathrm{CDCl}_{3}\right) \delta$ : $8.26(\mathrm{~s}, 1 \mathrm{H}), 6.77(\mathrm{~s}, 1 \mathrm{H}), 5.76(\mathrm{~s}, 1 \mathrm{H}), 4.81(\mathrm{~s}, 2 \mathrm{H}), 3.88(\mathrm{~s}, 4 \mathrm{H}), 3.81-3.58(\mathrm{~m}, 12 \mathrm{H}), 3.22(\mathrm{~s}, 2 \mathrm{H}) ;{ }^{13} \mathrm{C} \mathrm{NMR}(101$ $\left.\mathrm{MHz}, \mathrm{CDCl}_{3}\right) \delta: 162.1,161.5,161.3,158.6,151.0,137.9,124.3,120.3,105.0,92.7,78.0,67.3,67.0,46.0,44.3$. 
<smiles>Nc1cc(-c2cc(Nc3cccc(N4CCOCC4)c3)nc(N3CCOCC3)c2)cnc1F</smiles>

Yield 21.83\%. HPLC purity 99.39\% (Chiralcel OD-H, $0.5 \mathrm{~mL} / \mathrm{min}$, hexane $/ i-\mathrm{PrOH}=60 / 40, t=19.08 \mathrm{~min}$ ). HRMS (ESI): $m / z[\mathrm{M}+\mathrm{H}]^{+}$calcd. for $\left[\mathrm{C}_{24} \mathrm{H}_{27} \mathrm{~F}_{3} \mathrm{~N}_{7} \mathrm{O}_{2}\right]^{+}: 502.2173$, found: $502.2203 ;{ }^{1} \mathrm{H} \mathrm{NMR}\left(400 \mathrm{MHz}, \mathrm{CDCl}_{3}\right) \delta$ : $8.28(\mathrm{~s}, 1 \mathrm{H}), 7.36(\mathrm{~s}, 1 \mathrm{H}), 7.18(\mathrm{t}, J=8.1 \mathrm{~Hz}, 1 \mathrm{H}), 7.09-6.97(\mathrm{~m}, 2 \mathrm{H}), 6.76(\mathrm{~s}, 1 \mathrm{H}), 6.62-6.53(\mathrm{~m}, 1 \mathrm{H}), 6.10(\mathrm{~s}, 1 \mathrm{H})$, $4.86(\mathrm{~s}, 2 \mathrm{H}), 3.88-3.75(\mathrm{~m}, 8 \mathrm{H}), 3.65$ (s, 4H), 3.21-3.09 (m, 4H); ${ }^{13} \mathrm{C} \mathrm{NMR}\left(101 \mathrm{MHz}, \mathrm{CDCl}_{3}\right) \delta: 163.1,162.8$, $159.4,158.9,151.9,150.9,141.0,137.6,129.4,123.5,121.4,111.1,109.7,106.7,104.7,94.9,67.0,66.5,49.5$, 44.5.

\subsubsection{4-(6-Amino-4-(trifluoromethyl)pyridin-3-yl)-N-(4-(4-(methylsulfonyl)piperazin-1-yl)phenyl)-6- morpholinopyrimidin-2-amine (5o)}<smiles>CO[N+]1(C)CCN(c2ccc(Nc3nc(-c4cnc(N)cc4C(F)(F)F)cc(N4CCOCC4)n3)cc2)CC1</smiles>

Yield 19.33\%. HPLC purity 98.50\% (Chiralcel OD-H, $0.5 \mathrm{~mL} / \mathrm{min}$, hexane $/ i-\mathrm{PrOH}=60 / 40, t=8.21 \mathrm{~min}$ ). HRMS (ESI): $m / z[\mathrm{M}+\mathrm{H}]^{+}$calcd. for $\left[\mathrm{C}_{25} \mathrm{H}_{30} \mathrm{~F}_{3} \mathrm{~N}_{8} \mathrm{O}_{3} \mathrm{~S}\right]^{+}: 579.2108$, found: 579.2132; ${ }^{1} \mathrm{H}$ NMR (400 MHz, DMSO- $\left.d_{6}\right) \delta: 8.85(\mathrm{~s}, 1 \mathrm{H}), 8.09(\mathrm{~s}, 1 \mathrm{H}), 7.57(\mathrm{~d}, J=8.8 \mathrm{~Hz}, 2 \mathrm{H}), 6.85(\mathrm{~d}, J=8.8 \mathrm{~Hz}, 2 \mathrm{H}), 6.78(\mathrm{~s}, 1 \mathrm{H}), 6.67(\mathrm{~s}, 2 \mathrm{H})$, $6.21(\mathrm{~s}, 1 \mathrm{H}), 3.66(\mathrm{~s}, 4 \mathrm{H}), 3.57(\mathrm{~s}, 4 \mathrm{H}), 3.21(\mathrm{~s}, 4 \mathrm{H}), 3.11(\mathrm{~s}, 4 \mathrm{H}), 2.90(\mathrm{~s}, 3 \mathrm{H}), 2.48(\mathrm{~s}, 3 \mathrm{H}) ;{ }^{13} \mathrm{C} \mathrm{NMR}(101 \mathrm{MHz}$, DMSO- $\left.d_{6}\right) \delta: 162.9,162.7,160.1,159.2,150.5,145.0,135.3,134.2,133.7,121.0,120.0,116.8,103.8,94.1,66.0$, $49.2,45.6,44.0,34.0$.

\subsubsection{6 (4-((4-(6-Amino-4-(trifluoromethyl)pyridin-3-yl)-6-morpholinopyrimidin-2-yl)amino)phenyl)(4-} (methyl sulfonyl)piperazin-1-yl)methanone (5p)<smiles>COS(=O)(=O)N1CCN(C(=O)c2ccc(Nc3nc(-c4cnc(N)cc4C(F)(F)F)cc(N4CCOCC4)n3)cc2)CC1</smiles>

Yield 19.80\%. HPLC purity 99.39\% (Chiralcel OD-H, $0.5 \mathrm{~mL} / \mathrm{min}$, hexane $/ i-\mathrm{PrOH}=60 / 40, t=19.08 \mathrm{~min}$ ). HRMS (ESI): $m / z[\mathrm{M}+\mathrm{H}]^{+}$calcd. for $\left[\mathrm{C}_{26} \mathrm{H}_{30} \mathrm{~F}_{3} \mathrm{~N}_{8} \mathrm{O}_{4} \mathrm{~S}\right]^{+}: 607.2057$, found: $607.2049 ;{ }^{1} \mathrm{H} \mathrm{NMR}\left(400 \mathrm{MHz}, \mathrm{CDCl}_{3}\right) \delta$ : $8.28(\mathrm{~s}, 1 \mathrm{H}), 7.64(\mathrm{~d}, J=8.6 \mathrm{~Hz}, 2 \mathrm{H}), 7.37$ (d, $J=8.5 \mathrm{~Hz}, 2 \mathrm{H}), 6.78(\mathrm{~s}, 1 \mathrm{H}), 6.16(\mathrm{~s}, 1 \mathrm{H}), 4.89(\mathrm{~s}, 2 \mathrm{H}), 3.79(\mathrm{dd}, J=$ 
14.2, $9.1 \mathrm{~Hz}, 8 \mathrm{H}), 3.65(\mathrm{~d}, J=4.5 \mathrm{~Hz}, 4 \mathrm{H}), 3.24(\mathrm{~s}, 4 \mathrm{H}), 2.80(\mathrm{~s}, 3 \mathrm{H}) ;{ }^{13} \mathrm{C} \mathrm{NMR}\left(101 \mathrm{MHz}, \mathrm{CDCl}_{3}\right) \delta: 170.8,163.1$, $162.9,159.0,150.9,142.2,128.5,127.3,124.3,123.3,121.5,118.3,104.9,100.1,95.7,66.5,45.9,44.5,34.8$.

\subsection{General procedure for the preparation of 2-substituted-4,6-dichloro-1,3,5-triazines 9a-b}

To a solution of DIPEA (1.0 equiv.) and morpholine (1.0 equiv.) in $\mathrm{CH}_{2} \mathrm{Cl}_{2}(20 \mathrm{~mL})$ was added 2,4,6-trichloro-1,3,5-triazine 8 (1.1 equiv.) in $\mathrm{CH}_{2} \mathrm{Cl}_{2}(20 \mathrm{~mL})$ at $-5{ }^{\circ} \mathrm{C}$ slowly. The mixture was stirred at $-5{ }^{\circ} \mathrm{C}$ for $1 \mathrm{~h}$ and $0{ }^{\circ} \mathrm{C}$ overnight. The solution was diluted with $\mathrm{CH}_{2} \mathrm{Cl}_{2}(50 \mathrm{~mL})$, washed with $1 \mathrm{M} \mathrm{HCl}(50 \mathrm{~mL} \times 2)$ and brine $(50 \mathrm{~mL} \times 1)$ in turn, dried over $\mathrm{Na}_{2} \mathrm{SO}_{4}$. The solvent was removed under reduced pressure, the residue was purified by column chromatography (PE/EtOAc $=10 / 1$ to $5 / 1$ ) to afford 9a as white solid in $59.74 \%$ yield.

Compound $\mathbf{9 b}$ was prepared following the similar procedure mentioned above.

\subsubsection{4-(4,6-diChloro-1,3,5-triazin-2-yl)morpholine $(9 a)^{9}$}<smiles>Clc1nc(Cl)nc(N2CCOCC2)n1</smiles>

Yield 59.74\%. ESI-MS (m/z): $235.1[\mathrm{M}+\mathrm{H}]{ }^{+} ;{ }^{1} \mathrm{H}$ NMR (400 MHz, $\left.\mathrm{CDCl}_{3}\right)$ 8: 3.97-3.80 (m, 4H), 3.80-3.65 (m, $4 \mathrm{H})$.

\subsection{2 (2S,6R)-4-(4,6-diChloro-1,3,5-triazin-2-yl)-2,6-dimethylmorpholine (9b)}

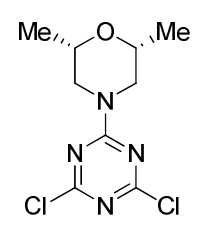

Yield 74.42\%. ESI-MS (m/z): $263.10[\mathrm{M}+\mathrm{H}]^{+} ;{ }^{1} \mathrm{H}$ NMR $\left(400 \mathrm{MHz}, \mathrm{CDCl}_{3}\right) \delta: 4.56(\mathrm{~d}, J=13.1 \mathrm{~Hz}, 2 \mathrm{H}), 3.59$ $(\mathrm{m}, 2 \mathrm{H}), 2.67(\mathrm{dd}, J=13.3,10.8 \mathrm{~Hz}, 2 \mathrm{H}), 1.25(\mathrm{~d}, J=6.2 \mathrm{~Hz}, 6 \mathrm{H}) ;{ }^{13} \mathrm{C}$ NMR $\left(101 \mathrm{MHz}, \mathrm{CDCl}_{3}\right) \delta: 170.7,164.0$, $71.6,49.3,18.7$.

\subsection{General procedure for the preparation of 2-chloro-4,6-disubstituted-1,3,5-triazines 10a-e}

To a solution of 2-substituted-4,6-dichloro-1,3,5-triazine 10a (1.0 equiv.) in THF (10 mL) was added $(1 R, 4 R)$-2-oxa-5-azabicyclo[2.2.1] heptane (28, 1.0 equiv.) and $\mathrm{K}_{2} \mathrm{CO}_{3}$ (1.5 equiv.). The mixture was stirred at room temperature overnight. Then the solvent was removed and the residue was dissolved in EtOAc $(50 \mathrm{~mL})$. The solution was washed with $\mathrm{H}_{2} \mathrm{O}(50 \mathrm{~mL})$ and brine $(50 \mathrm{~mL})$ in turn, dried over $\mathrm{Na}_{2} \mathrm{SO}_{4}$. The organic solvent was removed under reduced pressure, the residue was purified by column chromatography ( $\mathrm{PE} / \mathrm{EtOAc}=5 / 1)$ to afford $10 \mathrm{a}$ as white solid in $84.46 \%$ yield.

Compounds 10b-e were prepared following the similar procedure mentioned above. 


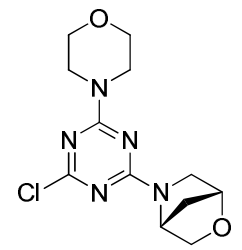

Yield 84.46\%. ESI-MS (m/z): $298.2[\mathrm{M}+\mathrm{H}]^{+} ;{ }^{1} \mathrm{H}$ NMR (400 MHz, $\left.\mathrm{CDCl}_{3}\right) \delta: 5.02(\mathrm{~d}, J=35.7 \mathrm{~Hz}, 1 \mathrm{H}), 4.67$ (s, 1H), 3.94-3.64 (m, 10H), $3.52(\mathrm{dt}, J=27.2,11.2 \mathrm{~Hz}, 4 \mathrm{H}) ;{ }^{13} \mathrm{C}$ NMR $\left(101 \mathrm{MHz}, \mathrm{CDCl}_{3}\right) \delta: 169.1,164.6,163.3$, $76.1,73.6,66.8,56.8,55.2,43.8,36.7$.

\subsection{2 (土)-(4aR,7aR)-6-(4-Chloro-6-morpholino-1,3,5-triazin-2-yl)hexahydro-2H-[1,4]dioxino[2,3-c]pyrrole} (10b)

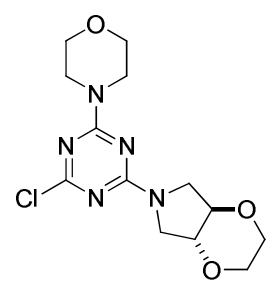

Yield 82.23\%. ESI-MS (m/z): $328.1[\mathrm{M}+\mathrm{H}]^{+} ;{ }^{1} \mathrm{H}$ NMR (400 MHz, $\left.\mathrm{CDCl}_{3}\right) \delta:$ 4.08-3.41 (m, 16H), 3.31-3.14 (m, 2H); ${ }^{13} \mathrm{C} \mathrm{NMR}\left(101 \mathrm{MHz}, \mathrm{CDCl}_{3}\right) \delta: 169.2,164.2,163.8,77.8,67.2,66.6,46.2,43.8$.

\subsection{3 (1R,4R)-5-(4-Chloro-6-((2S,6R)-2,6-dimethylmorpholino)-1,3,5-triazin-2-yl)-2-oxa-5-azabicyclo[2.2.1]} heptane (10c)

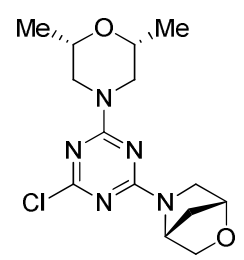

Yield 83.04\%. ESI-MS $(\mathrm{m} / \mathrm{z}): 326.2[\mathrm{M}+\mathrm{H}]^{+} ;{ }^{1} \mathrm{H}$ NMR $\left(400 \mathrm{MHz}, \mathrm{CDCl}_{3}\right) \delta: 5.01(\mathrm{~d}, J=28.1 \mathrm{~Hz}, 1 \mathrm{H}), 4.67$ (s, 1H), $4.51(\mathrm{~s}, 2 \mathrm{H}), 3.84(\mathrm{~s}, 2 \mathrm{H}), 3.65-3.39(\mathrm{~m}, 4 \mathrm{H}), 2.68-2.42(\mathrm{~m}, 2 \mathrm{H}), 2.02-1.80(\mathrm{~m}, 2 \mathrm{H}), 1.30-1.05(\mathrm{~m}, 6 \mathrm{H}) ;{ }^{13} \mathrm{C}$

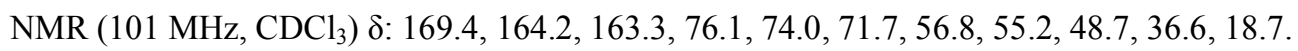

\subsection{4 (2S,2'S,6R,6'R)-4,4'-(6-Chloro-1,3,5-triazine-2,4-diyl)bis(2,6-dimethylmorpholine) (10d)}<smiles>CC1CN(c2nc(Cl)nc(N3CC(C)OC(C)C3)n2)CC(C)O1</smiles> 
Yield 76.53\%. ESI-MS ( $\mathrm{m} / \mathrm{z}): 342.2[\mathrm{M}+\mathrm{H}]{ }^{+} ;{ }^{1} \mathrm{H}$ NMR $\left(400 \mathrm{MHz}, \mathrm{CDCl}_{3}\right) \delta: 4.48(\mathrm{dd}, J=36.4,12.6 \mathrm{~Hz}, 4 \mathrm{H})$, $3.57(\mathrm{~s}, 4 \mathrm{H}), 2.56(\mathrm{t}, J=11.9 \mathrm{~Hz}, 4 \mathrm{H}), 1.23(\mathrm{~s}, 12 \mathrm{H}) ;{ }^{13} \mathrm{C} \mathrm{NMR}\left(101 \mathrm{MHz}, \mathrm{CDCl}_{3}\right) \delta: 169.5,164.2,71.6,48.8$, 18.8 .

2.6.5 (4aR,7aS)-6-(4-Chloro-6-((2S,6R)-2,6-dimethylmorpholino)-1,3,5-triazin-2-yl)hexahydro-2H-[1,4] dioxino[2,3-c]pyrrole (10e)

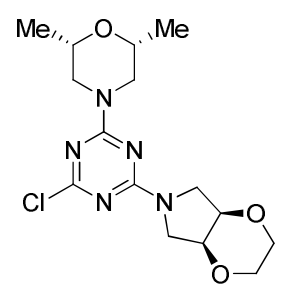

Yield 88.73\%. ESI-MS $(\mathrm{m} / \mathrm{z}): 356.2[\mathrm{M}+\mathrm{H}]^{+} ;{ }^{1} \mathrm{H}$ NMR $\left(400 \mathrm{MHz}, \mathrm{CDCl}_{3}\right) \delta: 4.52(\mathrm{~d}, J=13.3 \mathrm{~Hz}, 2 \mathrm{H}), 4.23$ $(\mathrm{s}, 2 \mathrm{H}), 3.92-3.72(\mathrm{~m}, 4 \mathrm{H}), 3.72-3.49(\mathrm{~m}, 6 \mathrm{H}), 2.56(\mathrm{t}, J=11.4 \mathrm{~Hz}, 2 \mathrm{H}), 1.23(\mathrm{~d}, J=5.8 \mathrm{~Hz}, 6 \mathrm{H}) ;{ }^{13} \mathrm{C}$ NMR $(101$ $\left.\mathrm{MHz}, \mathrm{CDCl}_{3}\right) \delta: 169.2,163.9,163.7,72.6,71.4,62.0,48.8,47.1,18.7$.

\subsection{General procedure for the preparation of 2,4,6-trisubstituted-1,3,5-triazines 11a-e}

Compounds 11a-e were prepared from 10a-e following the similar procedure for 5a-m.

\subsubsection{5-(4-((1R,4R)-2-Oxa-5-azabicyclo[2.2.1]heptan-5-yl)-6-morpholino-1,3,5-triazin-2-yl)-4-(trifluoro} methyl)pyridin-2-amine (11a)

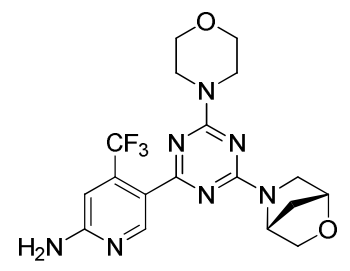

Yield 16.85\%. HPLC purity 95.32\% (Chiralcel OD-H, $0.5 \mathrm{~mL} / \mathrm{min}$, hexane $/ i-\mathrm{PrOH}=60 / 40, t=10.96 \mathrm{~min}$ ). HRMS (ESI): $m / z[\mathrm{M}+\mathrm{H}]^{+}$calcd. for $\left[\mathrm{C}_{18} \mathrm{H}_{21} \mathrm{~F}_{3} \mathrm{~N}_{7} \mathrm{O}_{2}\right]^{+}: 424.1703$, found: $424.1692 ;{ }^{1} \mathrm{H} \mathrm{NMR}\left(400 \mathrm{MHz}, \mathrm{CDCl}_{3}\right) \delta$ : $8.71(\mathrm{~s}, 1 \mathrm{H}), 6.77(\mathrm{~s}, 1 \mathrm{H}), 5.06(\mathrm{~d}, J=35.4 \mathrm{~Hz}, 1 \mathrm{H}), 4.95(\mathrm{~s}, 2 \mathrm{H}), 4.68(\mathrm{~s}, 1 \mathrm{H}), 3.93-3.46(\mathrm{~m}, 12 \mathrm{H}), 1.92(\mathrm{q}, J=$ $10.0 \mathrm{~Hz}, 1 \mathrm{H}), 1.84(\mathrm{~s}, 1 \mathrm{H}) ;{ }^{13} \mathrm{C} \mathrm{NMR}\left(101 \mathrm{MHz}, \mathrm{CDCl}_{3}\right) \delta: 169.5,164.6,163.6,159.4,152.6,138.4,122.5,121.5$, 105.3, 76.3, 74.1, 66.8, 56.6, 54.9, 43.6, 36.6.

\subsection{2 (土)-5-(4-((4aR,7aR)-dihydro-2H-[1,4]dioxino[2,3-c]pyrrol-6(3H,7H,7aH)-yl)-6-morpholino-1,3,5-} triazin-2-yl)-4-(trifluoromethyl)pyridin-2-amine (11b)<smiles>Nc1cc(C(F)(F)F)c(N2CCOCC2)nc1N1CC2OCCOC2C1</smiles>

Yield 7.80\%. HPLC purity 95.72\% (Chiralcel OD-H, $0.5 \mathrm{~mL} / \mathrm{min}$, hexane $/ i-\mathrm{PrOH}=60 / 40, t=12.72 \mathrm{~min}$ ). ESI-MS (m/z): $454.2[\mathrm{M}+\mathrm{H}]^{+} ;{ }^{1} \mathrm{H}$ NMR (400 MHz, $\left.\mathrm{CDCl}_{3}\right)$ 8: $8.72(\mathrm{~s}, 1 \mathrm{H}), 6.77(\mathrm{~s}, 1 \mathrm{H}), 4.90(\mathrm{~s}, 2 \mathrm{H}), 4.16-3.60(\mathrm{~m}$, 
16H), $3.26(\mathrm{dt}, J=14.9,10.0 \mathrm{~Hz}, 2 \mathrm{H}) ;{ }^{13} \mathrm{C} \mathrm{NMR}\left(101 \mathrm{MHz}, \mathrm{CDCl}_{3}\right) \delta: 169.7,164.5,163.9,159.8,152.7,138.1$, $122.3,105.3,99.7,78.0,67.3,66.8,45.8,43.6$.

2.7.3 5-(4-((1R,4R)-2-Oxa-5-azabicyclo[2.2.1]heptan-5-yl)-6-((2S,6R)-2,6-dimethylmorpholino)-1,3,5triazin-2-yl)-4-(trifluoromethyl)pyridin-2-amine (11c)<smiles>CO[C@H]1CN(c2nc(-c3cnc(N)cc3C(F)(F)F)nc(N3CC4CCC3O4)n2)C[C@H](O)O1</smiles>

Yield 20.05\%. HPLC purity $95.80 \%$ (Chiralcel OD-H, $0.5 \mathrm{~mL} / \mathrm{min}$, hexane $/ i-\mathrm{PrOH}=60 / 40, t=8.95 \mathrm{~min}$ ). HRMS (ESI): $m / z[\mathrm{M}+\mathrm{H}]^{+}$calcd. for $\left[\mathrm{C}_{20} \mathrm{H}_{24} \mathrm{~F}_{3} \mathrm{~N}_{7} \mathrm{O}_{2}\right]^{+}: 452.2016$, found: $452.2020 ;{ }^{1} \mathrm{H} \mathrm{NMR}\left(400 \mathrm{MHz}, \mathrm{CDCl}_{3}\right) \delta$ : $8.71(\mathrm{~s}, 1 \mathrm{H}), 6.77(\mathrm{~s}, 1 \mathrm{H}), 5.07(\mathrm{~d}, J=27.8 \mathrm{~Hz}, 1 \mathrm{H}), 4.95(\mathrm{~s}, 2 \mathrm{H}), 4.68(\mathrm{~s}, 2 \mathrm{H}), 4.61(\mathrm{~s}, 1 \mathrm{H}), 3.87(\mathrm{~d}, J=11.9 \mathrm{~Hz}$, 2H), 3.69-3.49 (m, 4H), $2.56(\mathrm{t}, J=11.8 \mathrm{~Hz}, 2 \mathrm{H}), 1.97-1.89(\mathrm{~m}, 2 \mathrm{H}), 1.23(\mathrm{~s}, 6 \mathrm{H}) ;{ }^{13} \mathrm{C} \mathrm{NMR}\left(101 \mathrm{MHz}, \mathrm{CDCl}_{3}\right) \delta$ : 169.2, 163.9, 163.3, 159.5, 152.4, 127.3, 122.0, 105.6, 100.0, 74.0, 71.6, 56.4, 55.0, 48.6, 36.5, 30.9, 18.7 .

\subsubsection{5-(4,6-bis((2S,6R)-2,6-diMethylmorpholino)-1,3,5-triazin-2-yl)-4-(trifluoromethyl)pyridin-2-amine (11d)}<smiles>Cc1cc(N)ncc1-c1nc(N2CC(C)O[C@@H](C)C2)nc(N2C[C@H](C)O[C@H](C)C2)n1</smiles>

Yield 10.10\%. HPLC purity 95.54\% (Chiralcel OD-H, $0.5 \mathrm{~mL} / \mathrm{min}$, hexane $/ i-\mathrm{PrOH}=60 / 40, t=7.17 \mathrm{~min}$ ). HRMS (ESI): $m / z[\mathrm{M}+\mathrm{H}]^{+}$calcd. for $\left[\mathrm{C}_{21} \mathrm{H}_{29} \mathrm{~F}_{3} \mathrm{~N}_{7} \mathrm{O}_{2}\right]^{+}: 468.2329$, found: $468.2312 ;{ }^{1} \mathrm{H} \mathrm{NMR}\left(400 \mathrm{MHz}, \mathrm{CDCl}_{3}\right) \delta$ : $8.71(\mathrm{~s}, 1 \mathrm{H}), 6.78(\mathrm{~s}, 1 \mathrm{H}), 4.91(\mathrm{~d}, J=9.8 \mathrm{~Hz}, 2 \mathrm{H}), 4.62(\mathrm{~d}, J=54.7 \mathrm{~Hz}, 4 \mathrm{H}), 3.61(\mathrm{~s}, 4 \mathrm{H}), 2.69-2.47(\mathrm{~m}, 4 \mathrm{H})$, 1.24(s, 12H); ${ }^{13} \mathrm{C}$ NMR (101 MHz, $\left.\mathrm{CDCl}_{3}\right) \delta: 170.0,164.7,159.5,152.7,138.1,124.3,122.3,105.3,71.7,48.8$, 19.0 .

\subsubsection{5-(4-((2S,6R)-2,6-diMethylmorpholino)-6-((4aR,7aS)-tetrahydro-2H-[1,4]dioxino[2,3-c]pyrrol-6(3H)-} yl)-1,3,5-triazin-2-yl)-4-(trifluoromethyl)pyridin-2-amine (11e)<smiles>C[C@H]1CN(c2nc(-c3cnc(N)cc3C(F)(F)F)nc(N3CC4OCCOC4C3)n2)C[C@@H](C)O1</smiles>

Yield 13.14\%. HPLC purity 98.35\% (Chiralcel OJ-H, $0.5 \mathrm{~mL} / \mathrm{min}$, hexane $/ i-\mathrm{PrOH}=60 / 40, t=9.20 \mathrm{~min}$ ). HRMS (ESI): $m / z[\mathrm{M}+\mathrm{H}]^{+}$calcd. for $\left[\mathrm{C}_{21} \mathrm{H}_{27} \mathrm{~F}_{3} \mathrm{~N}_{7} \mathrm{O}_{3}\right]^{+}: 482.2122$, found: $482.2120 ;{ }^{1} \mathrm{H} \mathrm{NMR}\left(400 \mathrm{MHz}, \mathrm{CDCl}_{3}\right) \delta$ : $8.73(\mathrm{~s}, 1 \mathrm{H}), 6.78(\mathrm{~s}, 1 \mathrm{H}), 4.85(\mathrm{~s}, 2 \mathrm{H}), 4.26(\mathrm{~s}, 2 \mathrm{H}), 4.00-3.80(\mathrm{~m}, 6 \mathrm{H}), 3.72-3.53(\mathrm{~m}, 6 \mathrm{H}), 2.57(\mathrm{t}, J=13.0 \mathrm{~Hz}$, 2H), 1.29-1.18 (m, 6H); ${ }^{13} \mathrm{C}$ NMR (101 MHz, $\left.\mathrm{CDCl}_{3}\right) \delta: 169.7,164.0,163.8,159.5,152.4,146.0,122.3,112.0$, 
105.3, 72.6, 71.4, 62.0, 48.8, 30.7, 19.0.

\subsection{General procedure for the preparation of 7-chloro-2,4-disubstitutedquinazolines 17a-b}

To a solution of 16 (1.0 equiv.) in DMF (10 mL) was added DIPEA (2.5 equiv.) and NaI (2.2 equiv.), followed by the addition of morpholine ( 2.5 equiv.). The mixture was heated to $80 \square$ for $8 \mathrm{~h}$, then cooled to rt and diluted with EtOAc $(50 \mathrm{~mL})$. The solution was washed with $\mathrm{H}_{2} \mathrm{O}(50 \mathrm{~mL} \times 5)$ and brine $(50 \mathrm{~mL})$ in turn, dried over $\mathrm{Na}_{2} \mathrm{SO}_{4}$. The organic solvent was removed under reduced pressure, the residue was purified by column chromatography $(\mathrm{PE} / \mathrm{EtOAc}=5 / 1)$ to afford $17 \mathrm{a}$ as yellow solid in $66.76 \%$ yield.

Compound $\mathbf{1 7 b}$ was prepared following the similar procedure mentioned above.

\subsubsection{4,4'-(7-Chloroquinazoline-2,4-diyl)dimorpholine (17a)}

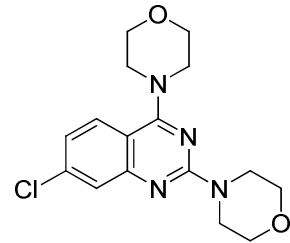

Yield 66.76\%. ESI-MS ( $/ \mathrm{z} / \mathrm{z}): 335.2[\mathrm{M}+\mathrm{H}]{ }^{+} ;{ }^{1} \mathrm{H}$ NMR $\left(400 \mathrm{MHz}, \mathrm{CDCl}_{3}\right) \delta: 7.58(\mathrm{~d}, J=8.8 \mathrm{~Hz}, 1 \mathrm{H}), 7.50(\mathrm{~d}$, $J=1.9 \mathrm{~Hz}, 1 \mathrm{H}), 7.01(\mathrm{dd}, J=8.8,1.7 \mathrm{~Hz}, 1 \mathrm{H}), 3.90-3.83(\mathrm{~m}, 8 \mathrm{H}), 3.80-3.74(\mathrm{~m}, 4 \mathrm{H}), 3.66-61(\mathrm{~m}, 4 \mathrm{H}) ;{ }^{13} \mathrm{C} \mathrm{NMR}$ $\left(101 \mathrm{MHz}, \mathrm{CDCl}_{3}\right) \delta: 165.4,158.8,155.3,138.6,126.2,125.4,121.5,110.3,67.0,66.6,50.4,44.5$.

\subsection{2 (2R,2'R,6S,6'S,)-4,4'-(7-Chloroquinazoline-2,4-diyl)bis(2,6-dimethylmorpholine) (17b)}<smiles>CO[C@H]1CN(c2nc(N3C[C@H](C)O[C@H](C)C3)c3ccc(Cl)cc3n2)C[C@@H](C)O1</smiles>

Yield 79.46\%. ESI-MS (m/z): $391.2[\mathrm{M}+\mathrm{H}]^{+} ;{ }^{1} \mathrm{H}$ NMR $\left(400 \mathrm{MHz}, \mathrm{CDCl}_{3}\right) \delta: 7.56(\mathrm{~d}, J=8.8 \mathrm{~Hz}, 1 \mathrm{H}), 7.49(\mathrm{~d}$, $J=1.6 \mathrm{~Hz}, 1 \mathrm{H}), 7.00(\mathrm{dd}, J=8.8,1.9 \mathrm{~Hz}, 1 \mathrm{H}), 4.64(\mathrm{~d}, J=12.8 \mathrm{~Hz}, 2 \mathrm{H}), 3.98(\mathrm{~d}, J=13.0 \mathrm{~Hz}, 2 \mathrm{H}), 3.90-78(\mathrm{~m}$, 2H), 3.71-3.59 (m, 2H), $2.84(\mathrm{dd}, J=12.7,10.8 \mathrm{~Hz}, 2 \mathrm{H}), 2.61(\mathrm{dd}, J=12.9,10.8 \mathrm{~Hz}, 2 \mathrm{H}), 1.26(\mathrm{dd}, J=13.8,6.2$ $\mathrm{Hz}, 12 \mathrm{H}) ;{ }^{13} \mathrm{C} \mathrm{NMR}\left(101 \mathrm{MHz}, \mathrm{CDCl}_{3}\right) \delta: 165.3,158.4,155.5,136.7,126.4,125.4,121.5,110.5,71.9,71.5,55.4$, 49.6, 18.8 .

2.9 General procedure for the preparation of 5-(2,4-disubstitutedquinazolin-7-yl)-4-(trifluoromethyl)pyridin-2amines 18a-b

Compounds 18a-e were prepared from $17 \mathbf{a}-\mathbf{b}$ following the similar procedure for $\mathbf{5 a}$.

\subsubsection{5-(2,4-diMorpholinoquinazolin-7-yl)-4-(trifluoromethyl)pyridin-2-amine (18a)}


<smiles>Nc1cc(-c2ccc3c(N4CCOCC4)nc(N4CCOCC4)nc3c2)c(C(F)(F)F)cn1</smiles>

Yield 31.64\%. HPLC purity 98.65\% (Chiralcel OD-H, $0.5 \mathrm{~mL} / \mathrm{min}$, hexane $/ i-\mathrm{PrOH}=60 / 40, t=14.84 \mathrm{~min}$ ). HRMS (ESI): $m / z[\mathrm{M}+\mathrm{H}]^{+}$calcd. for $\left[\mathrm{C}_{22} \mathrm{H}_{24} \mathrm{~F}_{3} \mathrm{~N}_{6} \mathrm{O}_{2}\right]^{+}: 461.1907$, found: $461.1898 ;{ }^{1} \mathrm{H} \mathrm{NMR}\left(400 \mathrm{MHz}, \mathrm{CDCl}_{3}\right) \delta$ : 8.10 (s, 1H), 7.68 (d, $J=8.5 \mathrm{~Hz}, 1 \mathrm{H}), 7.46(\mathrm{~s}, 1 \mathrm{H}), 7.02$ (d, $J=8.3 \mathrm{~Hz}, 1 \mathrm{H}), 6.80$ (s, 1H), $4.81(\mathrm{~s}, 2 \mathrm{H}), 3.99-3.60$ (m, 16H); ${ }^{13} \mathrm{C}$ NMR $\left(101 \mathrm{MHz}, \mathrm{CDCl}_{3}\right) \delta: 165.7,158.6,158.1,153.9,150.8,141.2,137.7,137.3,127.0,124.8$, $124.6,122.6,111.3,104.7,67.0,66.7,50.3,44.4$.

\subsubsection{5-(2,4-bis((2R,6S)-2,6-diMethylmorpholino)quinazolin-7-yl)-4-(trifluoromethyl)pyridin-2-amine (18b)}<smiles>CC1CN(c2nc(N3CC(C)OC(C)C3)c3ccc(-c4cnc(N)cc4C(F)(F)F)cc3n2)CC(C)O1</smiles>

Yield 18.50\%. HPLC purity 97.82\% (Chiralcel OJ-H, $0.5 \mathrm{~mL} / \mathrm{min}$, hexane $/ i-\mathrm{PrOH}=60 / 40, t=7.22 \mathrm{~min}$ ). HRMS (ESI): $m / z[\mathrm{M}+\mathrm{H}]^{+}$calcd. for $\left[\mathrm{C}_{26} \mathrm{H}_{32} \mathrm{~F}_{3} \mathrm{~N}_{6} \mathrm{O}_{2}\right]^{+}: 517.2533$, found: $517.2528 ;{ }^{1} \mathrm{H}$ NMR $\left(400 \mathrm{MHz}, \mathrm{CDCl}_{3}\right) \delta$ : $8.10(\mathrm{~s}, 1 \mathrm{H}), 7.66(\mathrm{~d}, J=8.5 \mathrm{~Hz}, 1 \mathrm{H}), 7.45(\mathrm{~s}, 1 \mathrm{H}), 7.01(\mathrm{~d}, J=8.3 \mathrm{~Hz}, 1 \mathrm{H}), 6.80(\mathrm{~s}, 1 \mathrm{H}), 4.82(\mathrm{~s}, 2 \mathrm{H}), 4.66(\mathrm{~d}, J=$ $12.5 \mathrm{~Hz}, 2 \mathrm{H}), 4.06(\mathrm{~d}, J=12.9 \mathrm{~Hz}, 2 \mathrm{H}), 3.88(\mathrm{dd}, J=8.6,6.3 \mathrm{~Hz}, 2 \mathrm{H}), 3.67$ (dd, $J=8.3,6.0 \mathrm{~Hz}, 2 \mathrm{H}), 2.87$ (dd, $J=$ 12.7, $10.8 \mathrm{~Hz}, 2 \mathrm{H}), 2.62(\mathrm{dd}, J=12.9,10.8 \mathrm{~Hz}, 2 \mathrm{H}), 1.26(\mathrm{t}, J=6.0 \mathrm{~Hz}, 12 \mathrm{H}) ;{ }^{13} \mathrm{C} \mathrm{NMR}\left(101 \mathrm{MHz}, \mathrm{CDCl}_{3}\right) \delta$ : $165.3,158.4,158.1,154.1,150.9,140.9,137.4,126.9,124.8,124.5,124.3,122.6,111.3,104.6,71.9,71.5,55.4$, 49.7, 19.0, 18.9.

\subsection{0 (士)-2-((4aR,7aR)-dihydro-2H-[1,4]dioxino[2,3-c]pyrrol-6(3H,7H,7aH)-yl)-6-morpholino-4,5'-}

bipyrimidin-2'-amine (21)

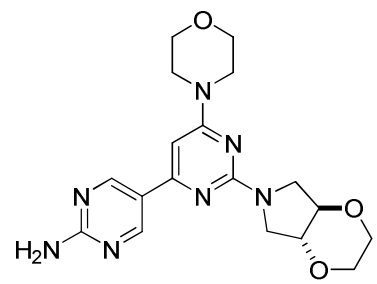

To a mixture of 4d (0.25 g, $0.77 \mathrm{mmol}, 1.0$ equiv.), 20 (0.34 g, $1.53 \mathrm{mmol}, 2.0$ equiv.) and $\mathrm{Pd}$ (dppf) $\mathrm{Cl}_{2} \cdot \mathrm{CH}_{2} \mathrm{Cl}_{2}\left(32 \mathrm{mg}, 0.038 \mathrm{mmol}, 0.05\right.$ equiv.) in degassed dioxane $(3.6 \mathrm{~mL})$ was added $2 \mathrm{M} \mathrm{K}_{2} \mathrm{CO}_{3}(1.20$ $\mathrm{mL}, 2.40 \mathrm{mmol}, 3.0$ equiv.). The mixture was heated under microwave to $150{ }^{\circ} \mathrm{C}$ for $2 \mathrm{~h}$. The solvent was removed and the residue was dissolved in EtOAc $(50 \mathrm{~mL})$, washed with $\mathrm{H}_{2} \mathrm{O}(30 \mathrm{~mL} \times 3)$ and brine $(30 \mathrm{~mL})$ in turn, dried over $\mathrm{Na}_{2} \mathrm{SO}_{4}$. The solvent was removed under reduced pressure, the crude product was first separated by column chromatography $(\mathrm{PE} / \mathrm{EtOAc}=5 / 1$ to $1 / 2)$, then further purified by column chromatography $\left(\mathrm{CH}_{2} \mathrm{Cl}_{2} / \mathrm{MeOH}=50 / 1\right)$ 
to give 21 as off-white solid (157 mg, 52.25\% yield). HPLC purity 98.95\% (Chiralcel OD-H, 0.5 mL/min, hexane $/ i-\mathrm{PrOH}=60 / 40, t=20.80 \mathrm{~min}$ ). HRMS (ESI): $m / z[\mathrm{M}+\mathrm{H}]^{+}$calcd. for $\left[\mathrm{C}_{18} \mathrm{H}_{24} \mathrm{~N}_{7} \mathrm{O}_{3}\right]^{+}: 386.1935$, found: 386.1916; ${ }^{1} \mathrm{H}$ NMR (400 MHz, DMSO-d $) \delta: 8.93$ (d, $\left.J=2.7 \mathrm{~Hz}, 2 \mathrm{H}\right), 6.99(\mathrm{~s}, 2 \mathrm{H}), 6.57(\mathrm{~s}, 1 \mathrm{H}), 3.83(\mathrm{t}, J=9.1 \mathrm{~Hz}$, 4H), 3.79-3.56 (m, 12H), 3.19-3.08 (m, 2H); ${ }^{13} \mathrm{C}$ NMR (101 MHz, DMSO- $\left.d_{6}\right) \delta: 164.1,163.3,159.8,159.3,156.8$, $119.9,86.4,78.0,66.5,65.9,45.8,44.0$.

\subsection{1 (-)-5-(2-((4aR,7aR)-diHydro-2H-[1,4]dioxino[2,3-c]pyrrol-6(3H,7H,7aH)-yl)-6-morpholinopyrimidin-4-} yl)-4-(trifluoromethyl)pyridin-2-amine (6)

$(-)$<smiles>Nc1cc(C(F)(F)F)c(-c2cc(N3CCOCC3)nc(N3CC4OCCOC4C3)n2)cn1</smiles>

The title compound was obtained via chiral preparative column (Phenomenex Lux, cellulose-2, $250 \times 10 \mathrm{~mm}$, $5 \mu \mathrm{m}$ ). HPLC purity 99.90\% (Phenomenex Lux, $3.0 \mathrm{~mL} / \mathrm{min}, \mathrm{MeOH} / \mathrm{H}_{2} \mathrm{O}=95 / 5, t=11.25 \mathrm{~min}$ ). HRMS (ESI): $\mathrm{m} / z$ $[\mathrm{M}+\mathrm{H}]^{+}$calcd. for $\left[\mathrm{C}_{20} \mathrm{H}_{24} \mathrm{~F}_{3} \mathrm{~N}_{6} \mathrm{O}_{3}\right]^{+}: 453.1856$, found: 453.1845; $[a]_{D}^{30}=-34.2\left(\mathrm{c}=0.20, \mathrm{CHCl}_{3}\right)$.

\subsection{2 (+)-5-(2-((4aS,7aS)-diHydro-2H-[1,4]dioxino[2,3-c]pyrrol-6(3H,7H,7aH)-yl)-6-morpholinopyrimidin-} 4-yl)-4-(trifluoromethyl)pyridin-2-amine (7)

$(+)$<smiles>Nc1cc(-c2cc(N3CCOCC3)nc(N3CC4OCCOC4C3)n2)c(C(F)(F)F)cn1</smiles>

The title compound was obtained via chiral preparative column (Phenomenex Lux, cellulose-2, $250 \times 10 \mathrm{~mm}$, $5 \mu \mathrm{m}$ ). HPLC purity 99.90\% (Phenomenex Lux, $3.0 \mathrm{~mL} / \mathrm{min}, \mathrm{MeOH} / \mathrm{H}_{2} \mathrm{O}=95 / 5, t=12.30 \mathrm{~min}$ ). HRMS (ESI): $\mathrm{m} / z$ $[\mathrm{M}+\mathrm{H}]^{+}$calcd. for $\left[\mathrm{C}_{20} \mathrm{H}_{24} \mathrm{~F}_{3} \mathrm{~N}_{6} \mathrm{O}_{3}\right]^{+}: 453.1856$, found: $453.1863 ;[a]_{D}^{30}=46.8\left(\mathrm{c}=0.21, \mathrm{CHCl}_{3}\right)$.

2.13 (-)-5-(4-((4aR,7aR)-dihydro-2H-[1,4]dioxino[2,3-c]pyrrol-6(3H,7H,7aH)-yl)-6-morpholino-1,3,5-triazin2-yl)-4-(trifluoromethyl)pyridin-2-amine (12)

$(-)$<smiles>Nc1cc(C(F)(F)F)c(-c2nc(N3CCOCC3)nc(N3CC4OCCOC4C3)n2)cn1</smiles> 
The title compound was obtained via chiral preparative column (Phenomenex Lux, cellulose-2, $250 \times 10 \mathrm{~mm}$, $5 \mu \mathrm{m}$ ). HPLC purity 97.70\% (Phenomenex Lux, $\left.3.0 \mathrm{~mL} / \mathrm{min}, \mathrm{MeOH} / \mathrm{H}_{2} \mathrm{O}=95 / 5, t=12.25 \mathrm{~min}\right)$. ESI-MS $(\mathrm{m} / \mathrm{z})$ : $454.2[\mathrm{M}+\mathrm{H}]^{+} ;[a]_{D}^{30}=-29.5\left(\mathrm{c}=0.21, \mathrm{CHCl}_{3}\right)$.

2.14 (+)-5-(4-((4aS,7aR)-dihydro-2H-[1,4]dioxino[2,3-c]pyrrol-6(3H,7H,7aH)-yl)-6-morpholino-1,3,5-triazin2-yl)-4-(trifluoromethyl)pyridin-2-amine (13)

$(+)$

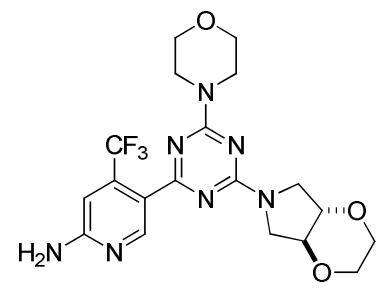

The title compound was obtained via chiral preparative column (Phenomenex Lux, cellulose-2, $250 \times 10 \mathrm{~mm}$, $5 \mu \mathrm{m}$ ). HPLC purity 98.62\% (Phenomenex Lux, $\left.3.0 \mathrm{~mL} / \mathrm{min}, \mathrm{MeOH} / \mathrm{H}_{2} \mathrm{O}=95 / 5, t=14.25 \mathrm{~min}\right)$. ESI-MS $(\mathrm{m} / z)$ : $454.2[\mathrm{M}+\mathrm{H}]^{+} ;[a]_{D}^{30}=50.7\left(\mathrm{c}=0.22, \mathrm{CHCl}_{3}\right)$.

\subsection{Preparation of $( \pm)-(4 a R, 7 a R)$ hexahydro-2H-[1,4]dioxino[2,3-c]pyrrole (26)}

\subsubsection{Benzyl 6-oxa-3-azabicyclo[3.1.0]hexane-3-carboxylate (23) ${ }^{10}$}

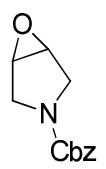

To a solution of 3-chlorobenzoperoxoic acid (10.55 g, $61.14 \mathrm{mmol})$ in $\mathrm{CH}_{2} \mathrm{Cl}_{2}$ (70 mL) was added benzyl 2,5-dihydro-1 $H$-pyrrole-1-carboxylate $22(10 \mathrm{~g}, 49.24 \mathrm{mmol})$ in $\mathrm{CH}_{2} \mathrm{Cl}_{2}(30 \mathrm{~mL})$ dropwise. The mixture was stirred at $\mathrm{rt}$ for $16 \mathrm{~h}$, and the formed precipitate was filtered off. Then the solution was washed with saturated $\mathrm{Na}_{2} \mathrm{~S}_{2} \mathrm{O}_{3}$ $(100 \mathrm{~mL} \times 1), \mathrm{NaHCO}_{3}(100 \mathrm{~mL} \times 1)$ and $\mathrm{NaCl}(100 \mathrm{~mL} \times 1)$ in turn, dried over $\mathrm{Na}_{2} \mathrm{SO}_{4}$. The solvent was removed under reduced pressure, the residue was further purified by column chromatography $(\mathrm{PE} / \mathrm{EtOAc}=3 / 1)$ to afford $\mathbf{2 3}$ (7.39 g, 68.49\% yield). ESI-MS (m/z): $220.2[\mathrm{M}+\mathrm{H}]^{+} ;{ }^{1} \mathrm{H}$ NMR (400 MHz, $\left.\mathrm{CDCl}_{3}\right)$ $\delta: ~ 7.41-7.29$ (m, 5H), 5.16-5.04 (m, 2H), $3.86(\mathrm{dd}, J=19.1,12.8 \mathrm{~Hz}, 2 \mathrm{H}), 3.73-3.63(\mathrm{~m}, 2 \mathrm{H}), 3.38(\mathrm{dd}, J=12.7,6.0 \mathrm{~Hz}, 2 \mathrm{H})$.

\subsection{2 (士)-(3R,4R)-benzyl 3-(2-bromoethoxy)-4-hydroxypyrrolidine-1-carboxylate (24)}

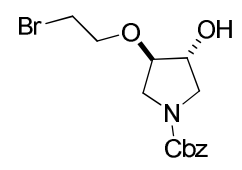

To a solution of $23(3.16 \mathrm{~g}, 14.42 \mathrm{mmol})$ in dry $\mathrm{CH}_{2} \mathrm{Cl}_{2}(40 \mathrm{~mL})$ was added 2-bromoethanol (1.97 $\mathrm{g}, 15.87$ $\mathrm{mmol})$ and $\mathrm{BF}_{3} \bullet \mathrm{Et}_{2} \mathrm{O}(0.22 \mathrm{~g}, 0.19 \mathrm{mmol})$ slowly. The mixture was stirred at rt overnight, then diluted with $\mathrm{CH}_{2} \mathrm{Cl}_{2}$ (30 mL). The solution was washed with $\mathrm{H}_{2} \mathrm{O}(50 \mathrm{~mL})$ and brine $(50 \mathrm{~mL})$ in turn, dried over $\mathrm{Na}_{2} \mathrm{SO}_{4}$. Then the 
solvent was removed and the residue was purified by column chromatography (PE/EtOAc $=1 / 2)$ to give $\mathbf{2 4}(1.44 \mathrm{~g}$, 29.03\% yield). ESI-MS (m/z): $344.2[\mathrm{M}+\mathrm{H}]{ }^{+} ;{ }^{1} \mathrm{H}$ NMR $\left(400 \mathrm{MHz}, \mathrm{CDCl}_{3}\right) \delta: 7.31(\mathrm{~d}, J=3.4 \mathrm{~Hz}, 5 \mathrm{H}), 5.09$ (s, 2H), $3.80(\mathrm{~d}, J=35.3 \mathrm{~Hz}, 3 \mathrm{H}), 3.63(\mathrm{td}, J=12.2,4.4 \mathrm{~Hz}, 2 \mathrm{H}), 3.56-3.28(\mathrm{~m}, 5 \mathrm{H}),{ }^{13} \mathrm{C} \mathrm{NMR}\left(101 \mathrm{MHz}, \mathrm{CDCl}_{3}\right) \delta: 155.7$, $137.1,128.5,128.0,127.8,83.3,82.5,73.3,72.4,69.4,66.9,30.4$.

\subsection{3 ( $( \pm)-(4 a R, 7 a R)$-benzyl tetrahydro-2H-[1,4]dioxino[2,3-c]pyrrole-6(3H)-carboxylate (25)}

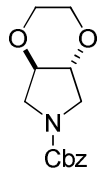

A solution of $\mathrm{KOH}(0.26 \mathrm{~g}, 4.59 \mathrm{mmol})$ in absolute ethanol $(3 \mathrm{~mL})$ was added to $24(1.43 \mathrm{~g}, 4.14 \mathrm{mmol})$ in ethanol $(10 \mathrm{~mL})$. The mixture was refluxed for $6 \mathrm{~h}$, the formed precipitate was filtered off and the cake was washed with EtOAc $(50 \mathrm{~mL})$. The organic layers were combined and concentrated to give a residue, which was further purified by column chromatography $(\mathrm{PE} / \mathrm{EtOAc}=1 / 1)$ to afford $25(0.74 \mathrm{~g}, 67.27 \%$ yield). ESI-MS $(\mathrm{m} / \mathrm{z}): 264.2$ $[\mathrm{M}+\mathrm{H}]^{+}$; LC-MS: $264.1(\mathrm{M}+1) ;{ }^{1} \mathrm{H} \mathrm{NMR}\left(400 \mathrm{MHz}, \mathrm{CDCl}_{3}\right) \delta: 7.35(\mathrm{~d}, J=4.6 \mathrm{~Hz}, 5 \mathrm{H}), 5.13(\mathrm{~d}, J=3.1 \mathrm{~Hz}, 2 \mathrm{H})$, 3.92-3.70 (m, 6H), $3.60(\mathrm{~s}, 2 \mathrm{H}), 3.15(\mathrm{dd}, J=9.5,4.6 \mathrm{~Hz}, 2 \mathrm{H}) ;{ }^{13} \mathrm{C} \mathrm{NMR}\left(101 \mathrm{MHz}, \mathrm{CDCl}_{3}\right) \delta: 155.2,136.4,128.5$, $128.1,128.0,76.6,67.5,61.2,45.5$.

\subsection{5 .4 ( \pm )-(4aR,7aR)-hexahydro-2H-[1,4]dioxino[2,3-c]pyrrole (26)}

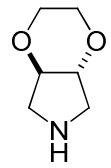

To a solution of $25(0.30 \mathrm{~g}, 1.14 \mathrm{mmol})$ in THF $(10 \mathrm{~mL})$ was added $10 \% \mathrm{Pd} / \mathrm{C}(0.10 \mathrm{~g})$. The mixture was stirred under $\mathrm{H}_{2}$ atmosphere at $\mathrm{rt}$ for $6 \mathrm{~h}$. Then the catalyst was filtered off, the solvent was removed to give $\mathbf{2 6}$, which was used for next step directly. ESI-MS $(\mathrm{m} / \mathrm{z}): 130.1[\mathrm{M}+\mathrm{H}]^{+}$.

\section{Enzyme assays}

In this study, the compounds were evaluated in terms of their ability to inhibit class I PI3K enzymes $\mathrm{P} 110 \alpha / \mathrm{p} 85$ and $\mathrm{p} 110 \delta / \mathrm{p} 85$ via the Kinase-Glo Luminescent Kinase Assays, as well as p110ß/p85 and p110 $/ \mathrm{p} 101$ via the ADP-Glo Luminescent Kinase Assay. PI3K reactions were performed in $50 \mathrm{mM}$ HEPES at pH 7.5 with 1 $\mathrm{mM}$ EGTA, $100 \mathrm{mM} \mathrm{NaCl}, 3 \mathrm{mM} \mathrm{MgCl} 2,2 \mathrm{mM}$ DTT, and 0.03\% CHAPS; all tested compounds were dissolved in $100 \%$ DMSO. PIP2 and ATP were used as substrates, and the final reaction volume was $10 \mu \mathrm{L}$. To evaluate the PI3K $\alpha$ inhibitors, $1.65 \mathrm{nM}$ enzyme, $50 \mu \mathrm{M}$ PIP2, and $25 \mu \mathrm{M}$ ATP were used for every $10 \mu \mathrm{L}$ reaction volume with inhibitor concentrations ranging from $0.5 \mathrm{nM}$ to $10 \mu \mathrm{M}$. After incubating for $1 \mathrm{~h}$ at room temperature, the reactions were quenched by adding $10 \mu \mathrm{L}$ of Kinase-Glo reagent ( $5 \mu \mathrm{L}$ of ADP-Glo reagent for $\mathrm{p} 110 \beta / \mathrm{p} 85$ and $\mathrm{p} 110 \gamma / \mathrm{p} 101)$. Raw data were collected from Flexstation program (SnygerMax for p110ק/p85 and p110 $/ \mathrm{p} 101$ ) and the $\mathrm{IC}_{50}$ values were defined via curves that plotted using Graphpad Prism software.

\section{Cell proliferation assay}

The following cell lines were used in the experiment: K562, HL60, Huh7, MOLT-4, MCF-7, DU145, U937, NCI-N87, HT1080, BGC-823, BEL-7402, A431, A549, Hela, SGC-7901, PANC-1, MDA-MB-231, PC3 and 
SK-BR-3. Cells were maintained at $37{ }^{\circ} \mathrm{C}$ in a $5 \% \mathrm{CO}_{2}$ incubator in RPMI1640 (Gibco, Invitrogen) or DMEM (Gibco, Invitrogen) containing 10\% fetal bovine serum (Gibco, Invitrogen). Cell proliferation was determined by CCK8 assay (DOjinDo, Japan). Cells were seeded data density of 800-1000 cells/well in 384 well plates and treated with various concentrations of compounds or the solvent control. After incubating for $72 \mathrm{~h}$, CCK8 reagent was added, and absorbance was measured at $450 \mathrm{~nm}$ by using Envision 2104 multi-label Reader (PerkinElmer, USA). All the experiments were repeated at least three times. Dose-response curves were plotted using Prism 5.0 (Graph Pad Software Inc., USA) to determine the $\mathrm{IC}_{50}$ values.

Cell viability in Figure 7 was assessed by WST-8 assay (Dojindo) according to the manufacturer's instructions. Cells were seeded in the 96-well plate. After different treatment, $10 \mu \mathrm{L}$ WST-8 solutions were added to each well and cells were incubated at $37{ }^{\circ} \mathrm{C}$ for $4 \mathrm{~h}$. The absorbance was finally determined at $450 \mathrm{~nm}$.

\section{Western blot assay}

Suppressive activities of Akt and phospho-Akt (p-Akt, S473) in U937 cells were determined by Western blot. U937 cells were treated with different compounds for $24 \mathrm{~h}$. Cell lysates were clarified by centrifugation at 12,000 rpm for $20 \mathrm{~min}$ at $4{ }^{\circ} \mathrm{C}$, and supernatant was collected. Equal amounts of protein were subjected to SDS-PAGE and transferred to nitrocellulose membranes (Merck Millipore, Billerica, MA, USA). The membrane were blocked and incubated overnight at $4{ }^{\circ} \mathrm{C}$ with primary antibodies against p-Akt, Akt (Cell Signaling Technology Corp., Beverly, MA, USA), and $\beta$-actin (Santa Cruz Biotechnology, Santa Cruz, CA, USA), followed by incubation with appropriate secondary antibodies. Antibody binding was detected with chemiluminescence reagents (Sigma-Aldrich, St. Louis, MO, USA).

\section{Tumor growth in xenografts}

MDA-MB-231 cells $\left(10^{6}\right)$ were injected into the right flank of 4-week-old female nude mice $(n=5)$. When the tumor size reached $50 \mathrm{~mm}^{3}$, mice were randomly distributed into two groups that were treated intragastrically every two days with either a vehicle control or with $30 \mathrm{mg} / \mathrm{kg} \mathbf{5 d}$ dissolved in PEG300. The tumor volumes $\left(\mathrm{A} \times \mathrm{B}^{2} / 2 ; \mathrm{A}\right.$ being the greatest diameter and B being the diameter perpendicular to A) were measured by calipers. Other indicators of general health, such as body weight, feeding behavior, and motor activity, of each animal were also monitored. After administering the drug or vehicle for 19 days, the mice were sacrificed and the tumor xenografts were immediately dissected and weighed. All animal procedures were approved by the Institutional Animal Care and Use Committee of the Sun Yat-sen University Cancer Center.

\section{References}

(1) Burger, M. T.; Pecchi, S.; Wagman, A.; Ni, Z.-J.; Knapp, M.; Hendrickson, T.; Atallah, G.; Pfister, K.; Zhang, Y.; Bartulis, S.; Frazier, K.; Ng, S.; Smith, A.; Verhagen, J.; Haznedar, J.; Huh, K.; Iwanowicz, E.; Xin, X.; Menezes, D.; Merritt, H.; Lee, I.; Wiesmann, M.; Kaufman, S.; Crawford, K.; Chin, M.; Bussiere, D.; Shoemaker, K.; Zaror, I.; Maira, S.-M.; Voliva, C. F. Identification of NVP-BKM120 as a potent, pelective, orally bioavailable class I PI3 kinase inhibitor for treating cancer. ACS Med. Chem. Lett. 2011, 2, 774-779.

(2) Cmiljanovic, V.; Cmiljanovic, N.; Giese, B.; Wymann, M. Triazine, pyrimidine and pyridine analogs and their use as therapeutic agents and diagnostic probes and their preparation. WO2010052569A2, 2010.

(3) Smits, R. A.; de Esch, I. J. P.; Zuiderveld, O. P.; Broeker, J.; Sansuk, K.; Guaita, E.; Coruzzi, G.; Adami, M.; Haaksma, E.; Leurs, R. Discovery of quinazolines as histamine H4 receptor inverse agonists using a scaffold hopping approach. J. Med. Chem. 2008, 51, 7855-7865.

(4) Zhang, J.; Zhang, Y.; Zhang, W.; Liu, B.; Zhang, J.; Liu, J.; Zhang, L. Preparation of quinazoline derivatives as inhibitors of protein tyrosine kinase. CN103102344A, 2013.

(5) Butora, G.; Goble, S. D.; Pastemak, A.; Yang, L.; Zhou, C.; Moyes, C. R. Preparation of tetrahydropyridopyridines and related compounds as modulators of chemokine receptor. US20080081803A1, 2008. 
(6) Tangallapally, R. P.; Yendapally, R.; Lee, R. E.; Lenaerts, A. J. M.; Lee, R. E. Synthesis and evaluation of cyclic secondary amine substituted phenyl and benzyl nitrofuranyl amides as novel antituberculosis agents. $J$. Med. Chem. 2005, 48, 8261-8269.

(7) Wang, S.; Midgley, C. A.; Scaërou, F.; Grabarek, J. B.; Griffiths, G.; Jackson, W.; Kontopidis, G.; McClue, S. J.; McInnes, C.; Meades, C.; Mezna, M.; Plater, A.; Stuart, I.; Thomas, M. P.; Wood, G.; Clarke, R. G.; Blake, D. G.; Zheleva, D. I.; Lane, D. P.; Jackson, R. C.; Glover, D. M.; Fischer, P. M. Discovery of N-phenyl-4-(thiazol-5-yl)pyrimidin-2-amine aurora kinase inhibitors. J. Med. Chem. 2010, 53, 4367-4378.

(8) Li, H.; Thota, S.; Carroll, D.; Argade, A.; Tso, K.; Sran, A.; Clough, J.; Keim, H.; Bhamidipati, S.; Taylor, V.; Cooper, R.; Singh, R.; Wong, B. Preparation of pyrimidine-2,4-diamines for inhibition of the JAK pathway. WO2006133426A2, 2006.

(9) Hummersone, M. G.; Gomez, S.; Menear, K. A.; Cockcroft, X.-L. F.; Smith, G. C. M. Preparation of methylenehydrazinotriazinediamine derivatives and related analogs as inhibitors of mTOR. WO2006090167A2, 2006.

(10) Pinson, J.-A.; Zheng, Z.; Miller, M. S.; Chalmers, D. K.; Jennings, I. G.; Thompson, P. E. l-Aminoacyl-triazine serivatives are isoform-selective PI3K $\beta$ inhibitors that target nonconserved Asp862 of PI3K $\beta$. ACS Med. Chem. Lett. 2012, 4, 206-210. 
7. ${ }^{1} \mathrm{H}$ NMR and ${ }^{13} \mathrm{C}$ NMR spectra for selected compounds

5-(2,6-diMorpholinopyrimidin-4-yl)-4-(trifluoromethyl)pyridin-2-amine (5a)

${ }^{1}$ H NMR
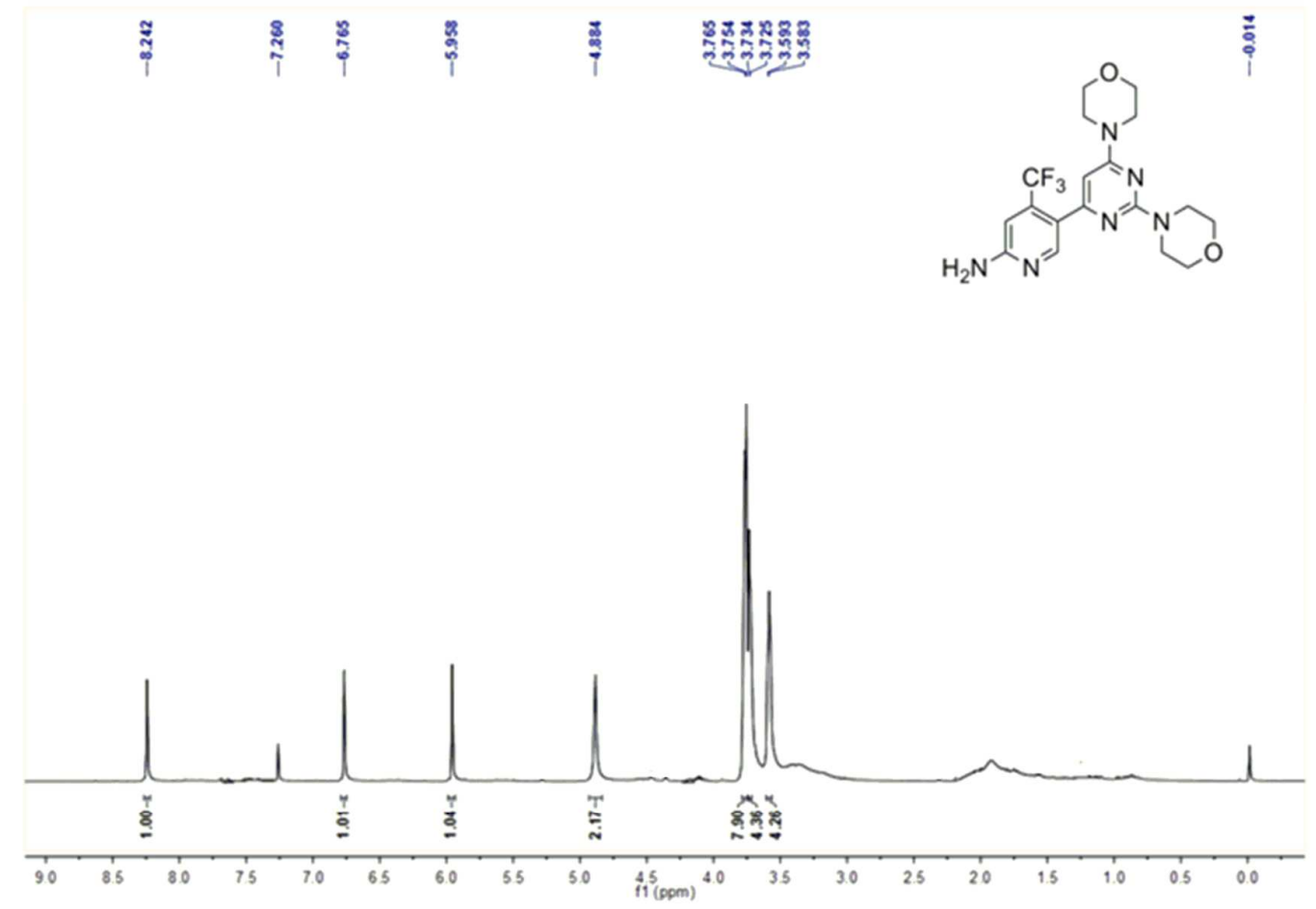

${ }^{13}$ C NMR

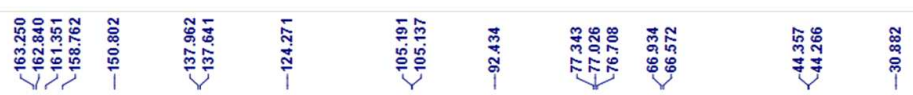

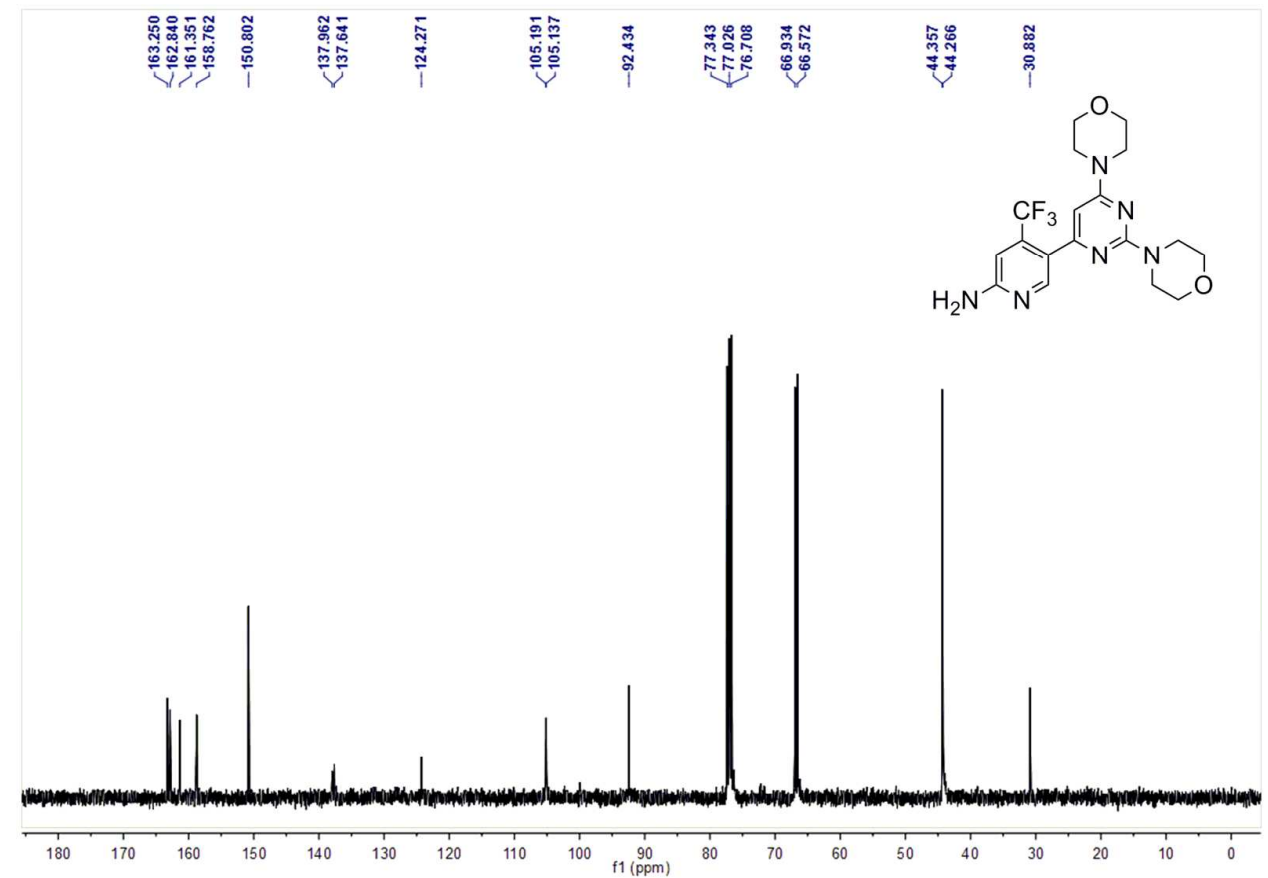


(土)-5-(2-((4aS,7aR)-diHydro-2H-[1,4]dioxino[2,3-c]pyrrol-6(3H,7H,7aH)-yl)-6-morpholinopyrimidin-4-yl)-4-(tri fluoromethyl)pyridin-2-amine (5d)

${ }^{1}$ H NMR

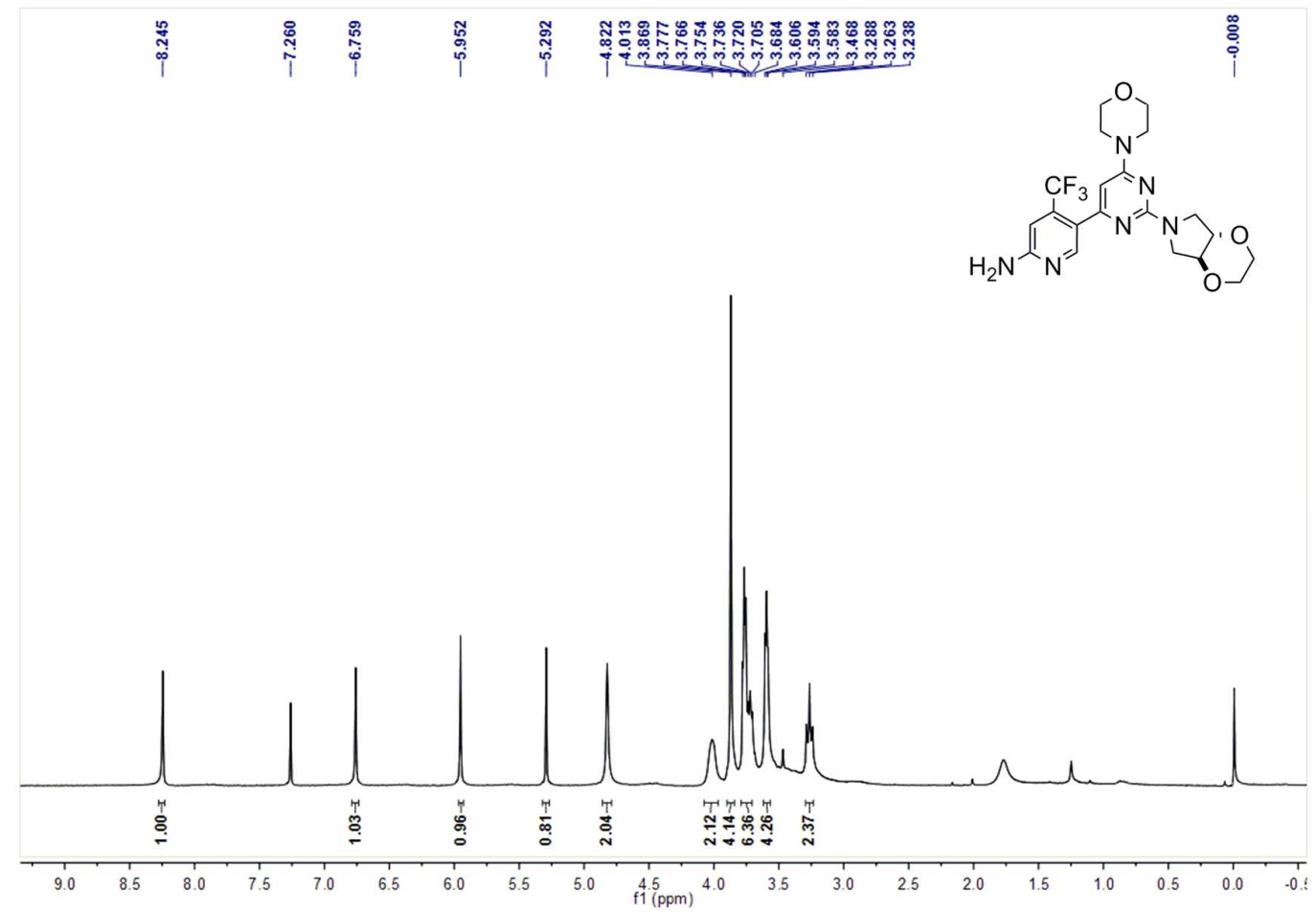

${ }^{13}$ C NMR

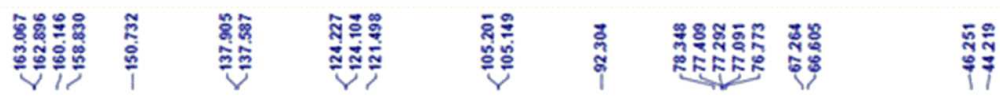

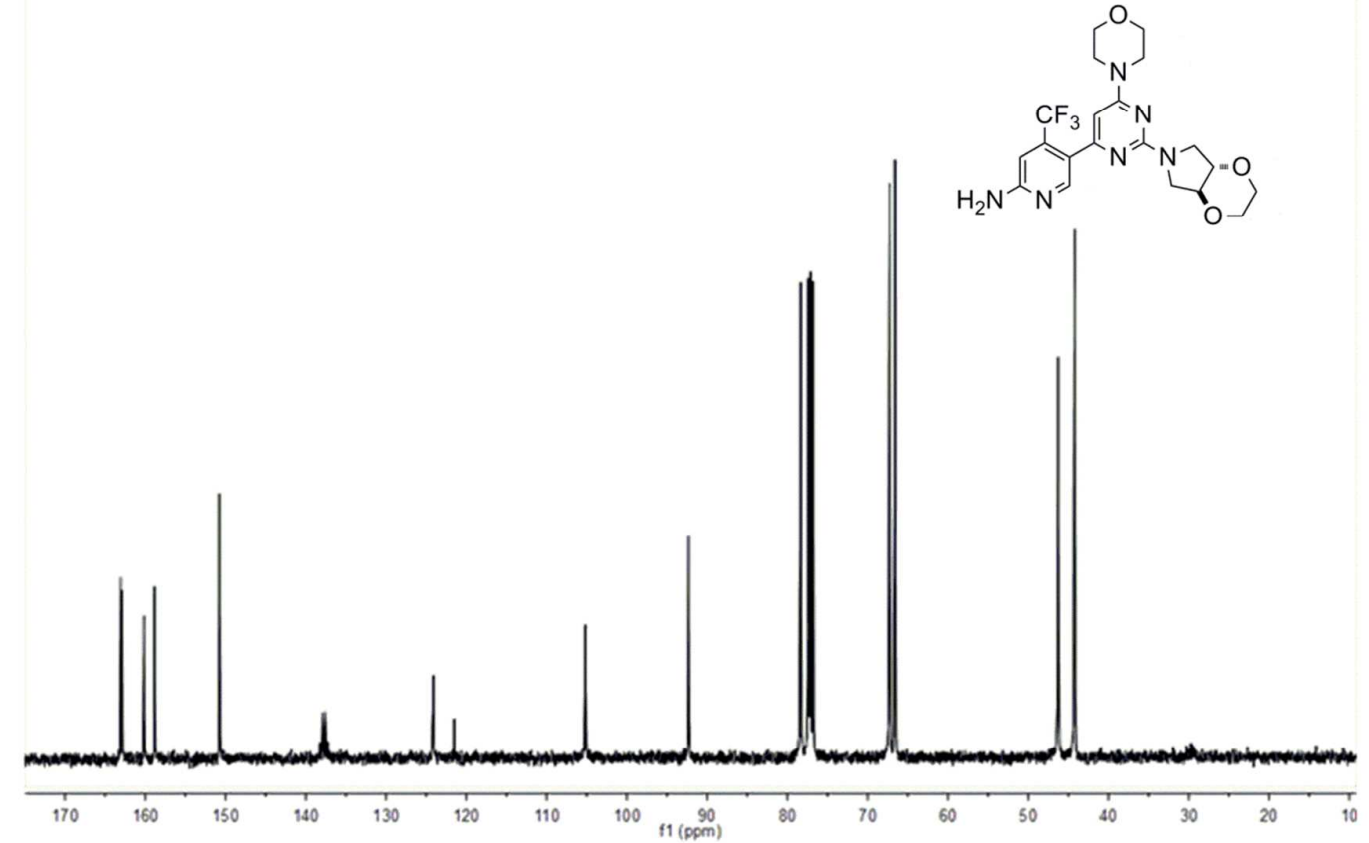


5-(2-(4-(Methylsulfonyl)piperazin-1-yl)-6-morpholinopyrimidin-4-yl)-4-(trifluoromethyl)pyridin-2-amine (5f)

${ }^{1}$ H NMR
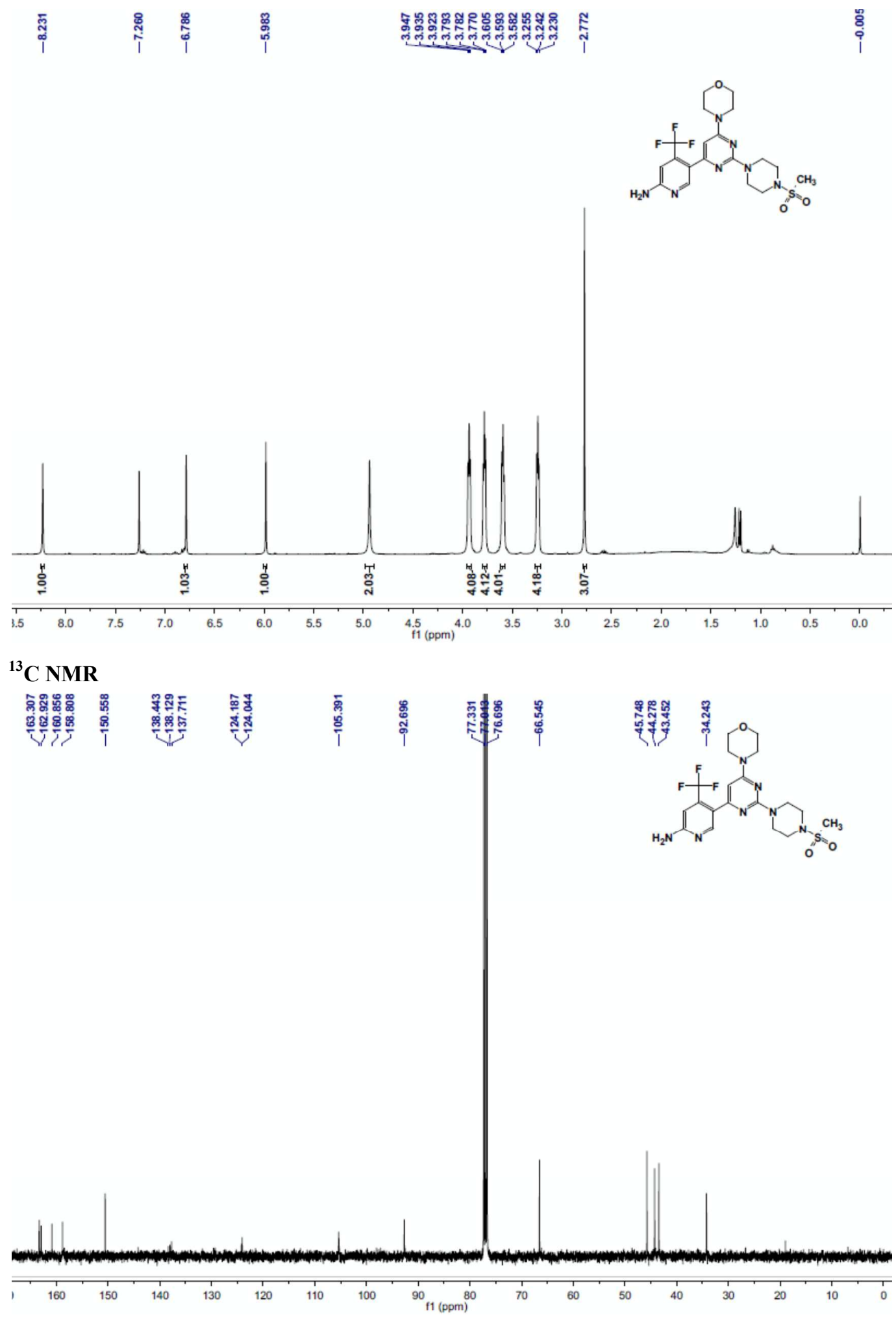
4-(6-Amino-4-(trifluoromethyl)pyridin-3-yl)-6-morpholino-N-(4-morpholinophenyl)pyrimidin-2-amine (5g) ${ }^{1}$ H NMR

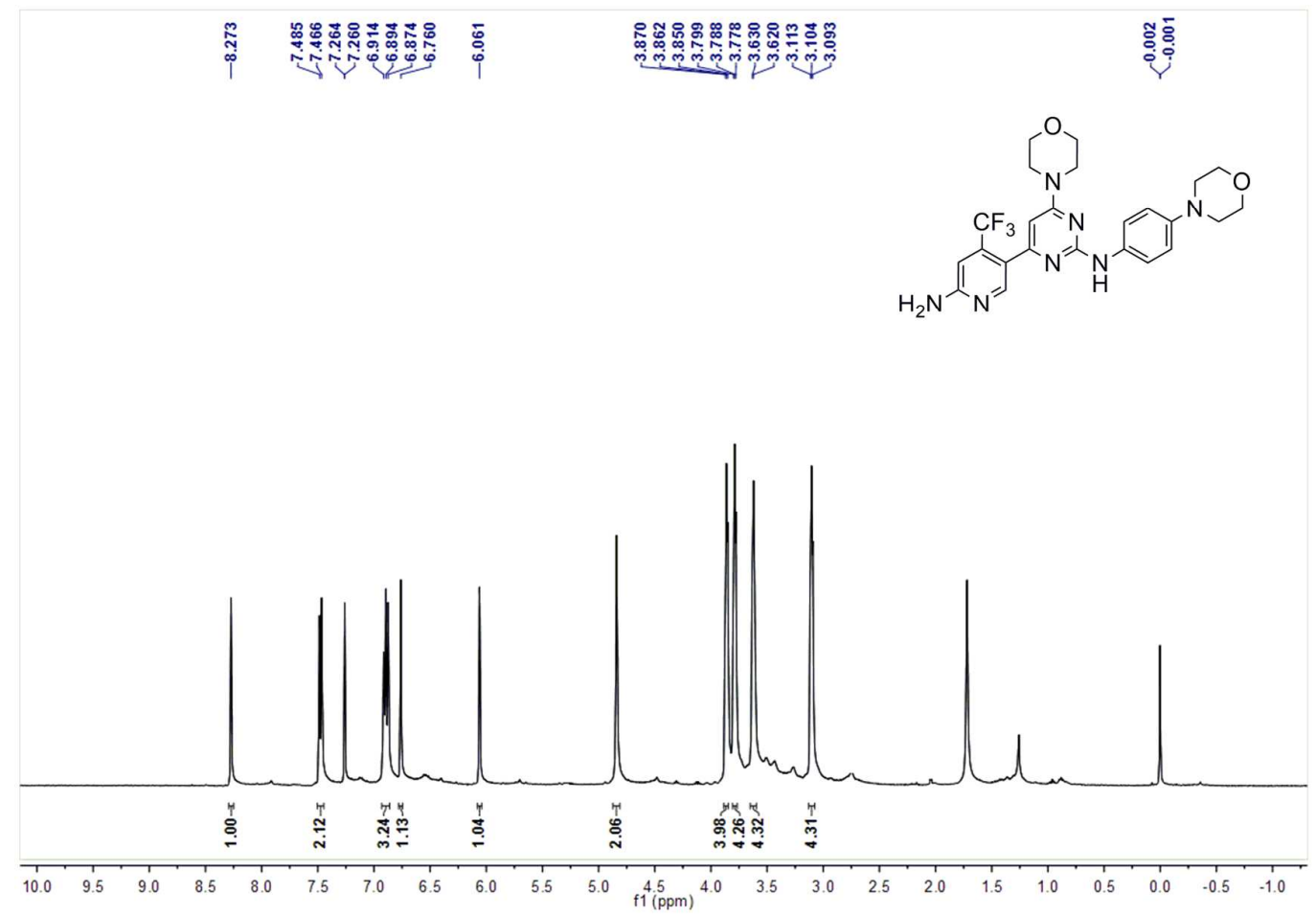

${ }^{13}$ C NMR

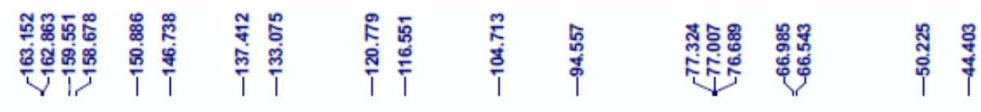

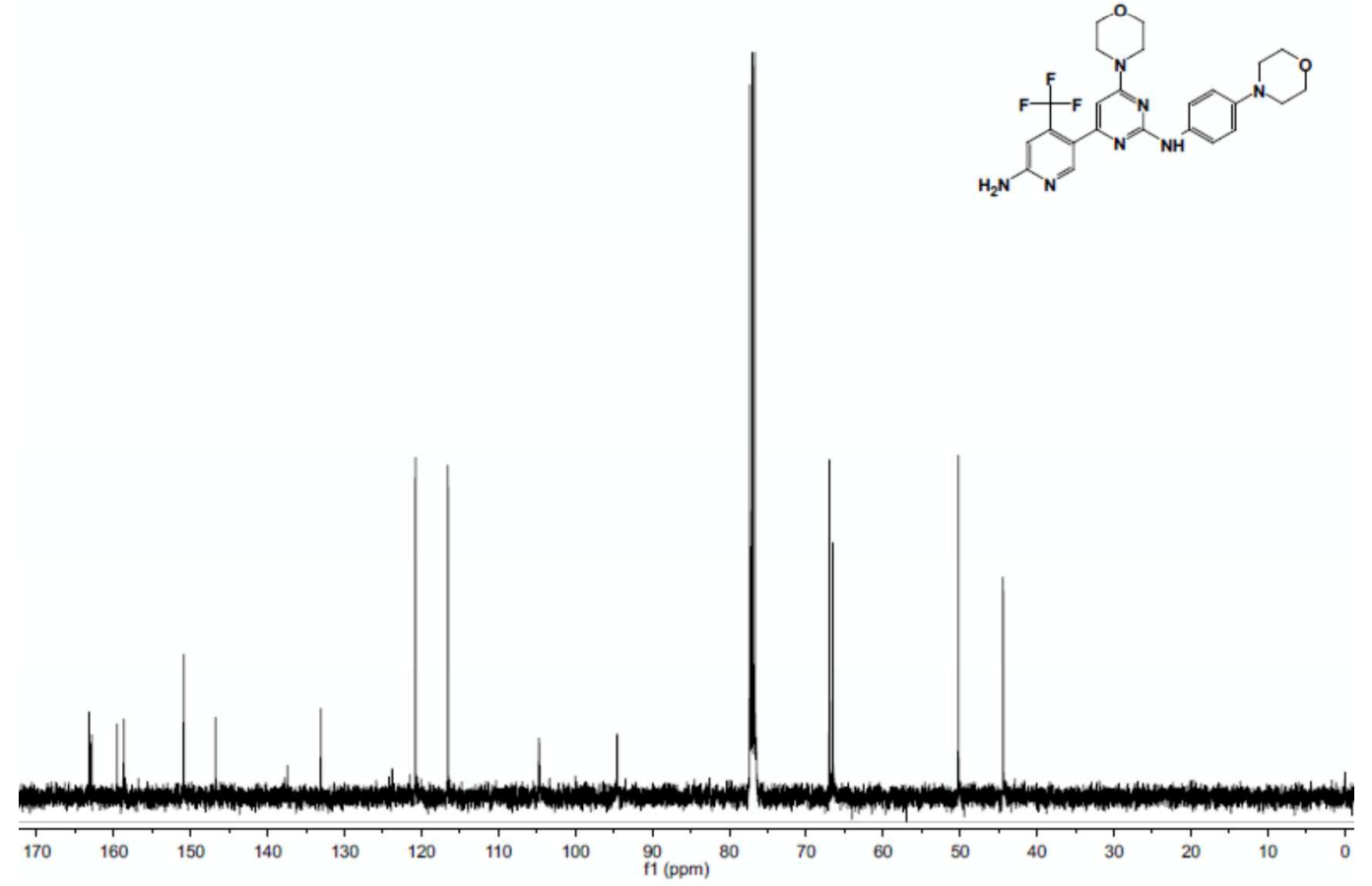


(4-((4-(6-Amino-4-(trifluoromethyl)pyridin-3-yl)-6-morpholinopyrimidin-2-yl)amino)phenyl)(4-(methylsulfonyl) piperazin-1-yl)methanone (5p)

${ }^{1}$ H NMR
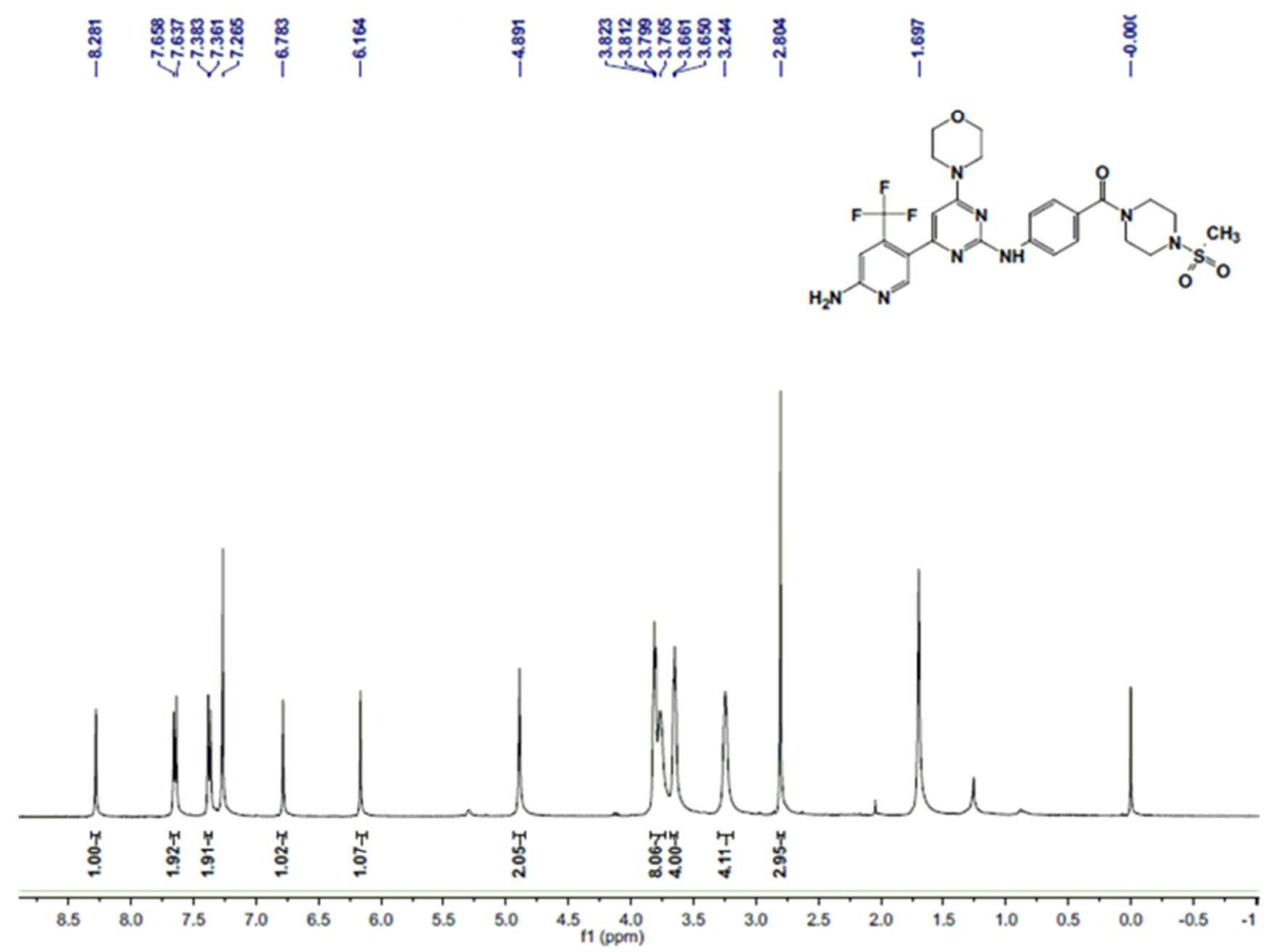

${ }^{13}$ C NMR

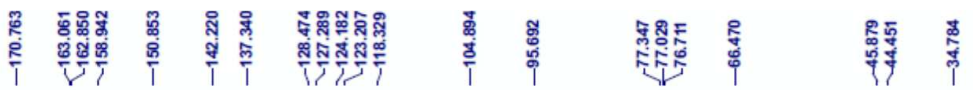

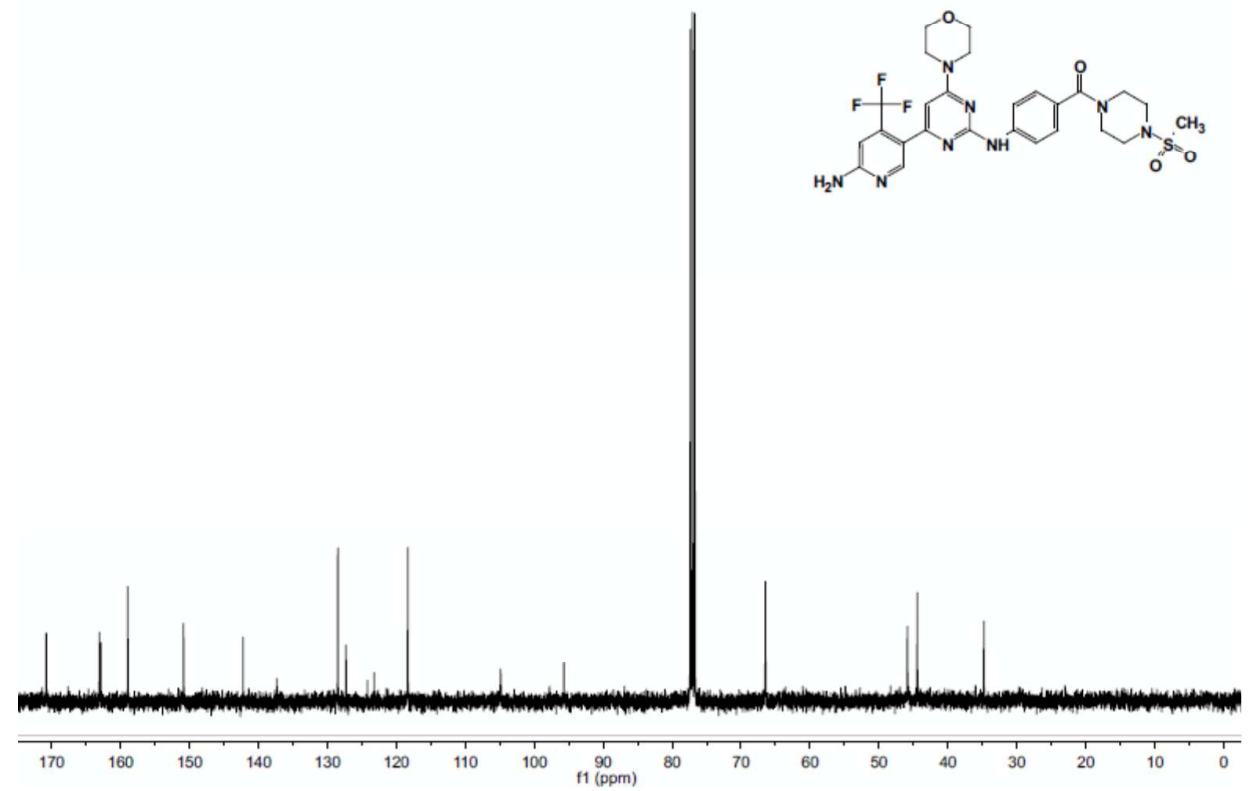


5-(2,4-diMorpholinoquinazolin-7-yl)-4-(trifluoromethyl)pyridin-2-amine (18a)

${ }^{1}$ H NMR

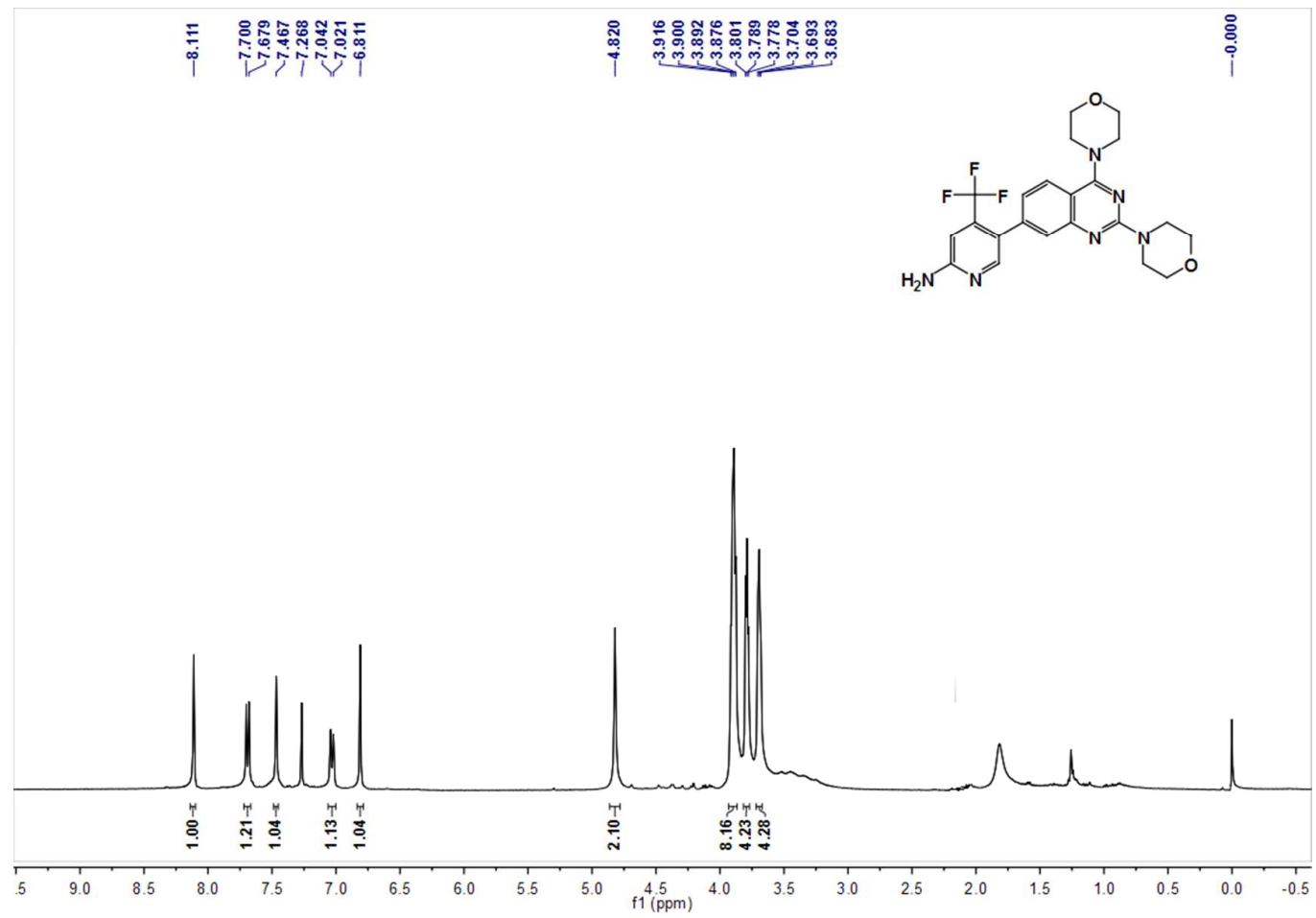

${ }^{13}$ C NMR

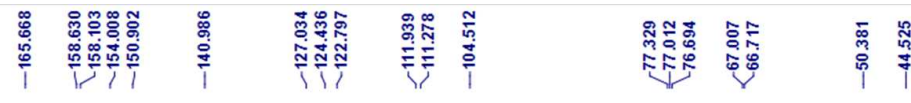

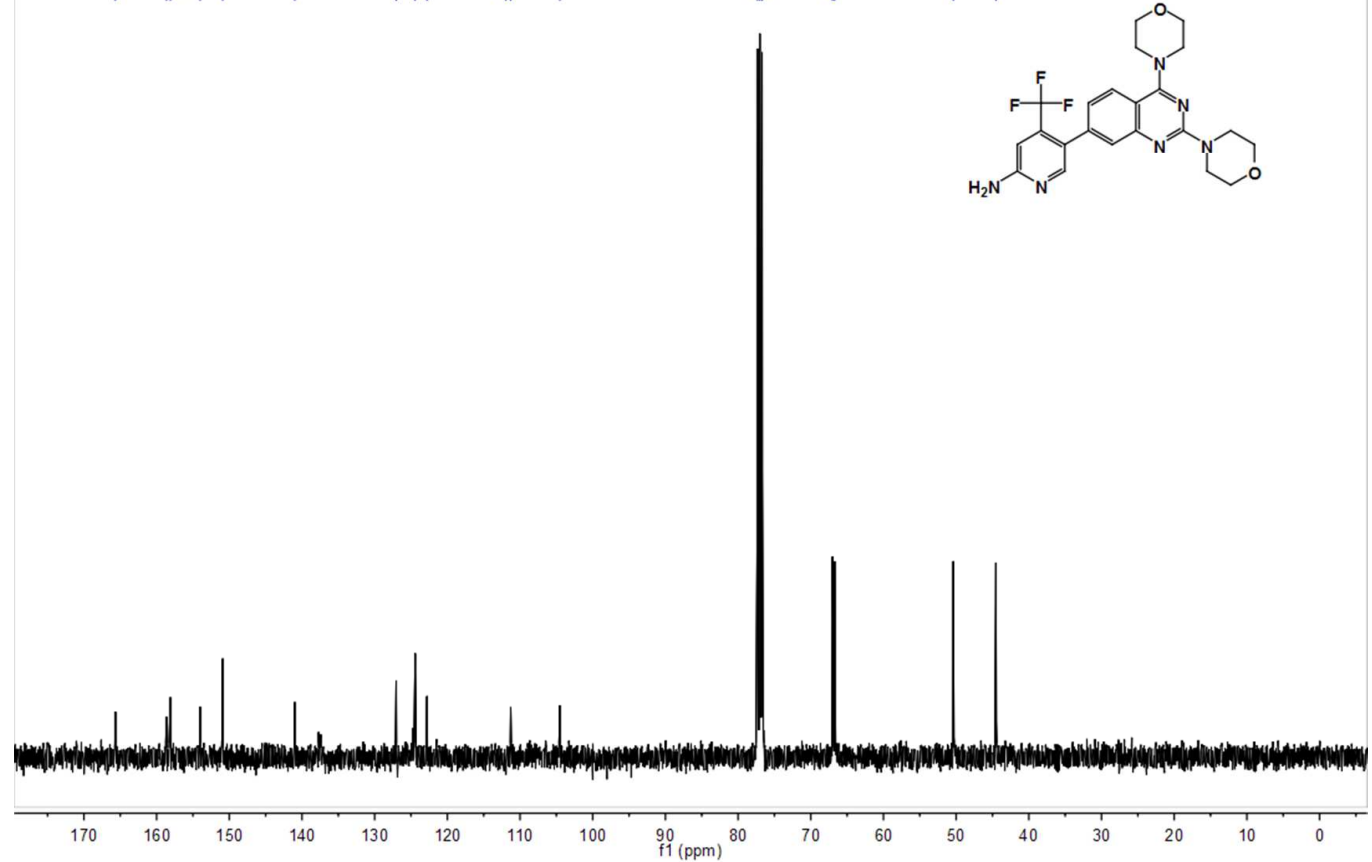


(土)-2-((4aR,7aR)-dihydro-2H-[1,4]dioxino[2,3-c]pyrrol-6(3H,7H,7aH)-yl)-6-morpholino-4,5'-bipyrimidin-2'-ami ne (21)

${ }^{1}$ H NMR

సิ

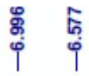

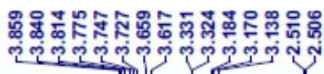
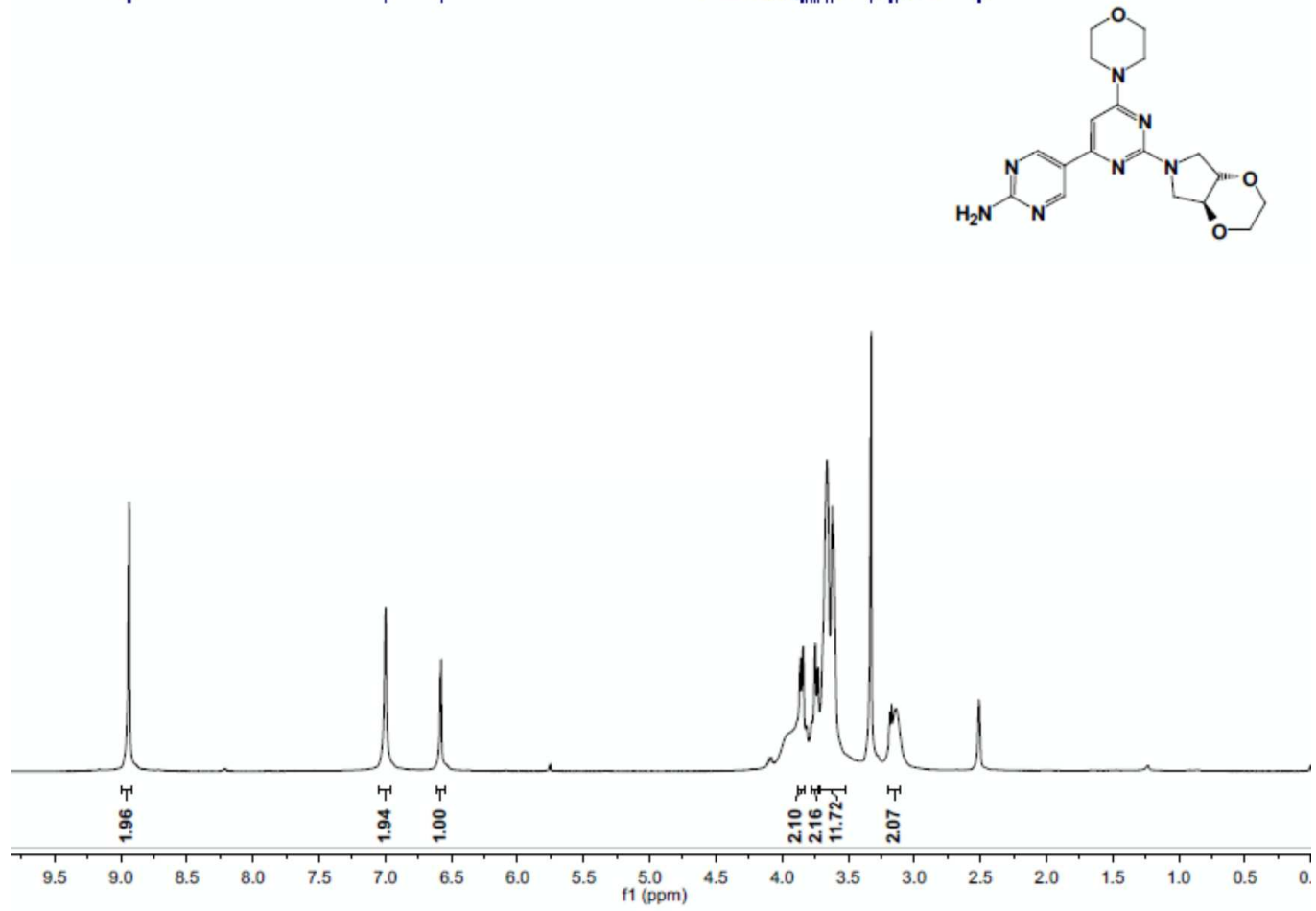

${ }^{13}$ C NMR

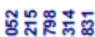

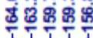

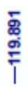

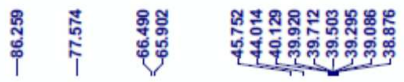

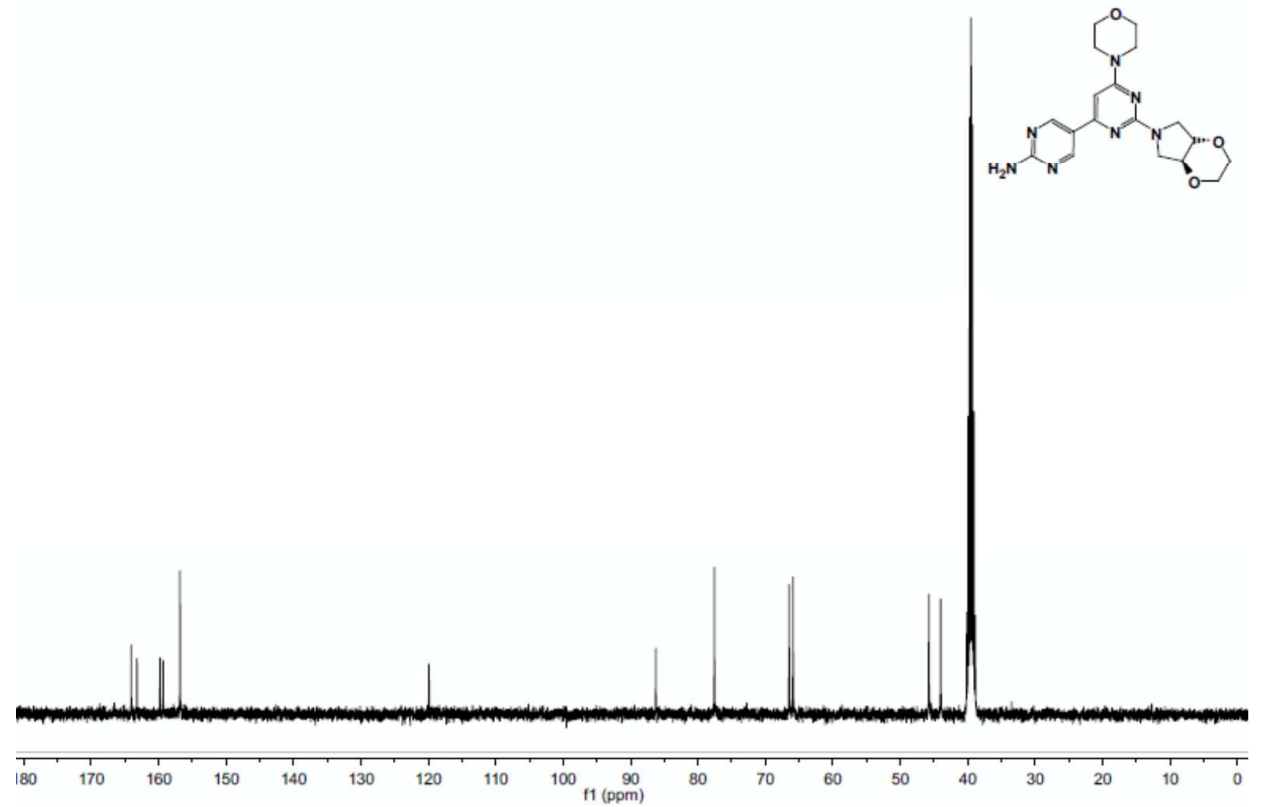

